\title{
Aircraft-based observations of air-sea fluxes over Denmark Strait and the Irminger Sea during high wind speed conditions
}

\author{
G. N. Petersen* and I. A. Renfrew \\ School of Environmental Sciences, University of East Anglia, UK
}

\begin{abstract}
During the Greenland Flow Distortion experiment (GFDex), aircraft-based observations of air-sea fluxes were obtained over Denmark Strait and the Irminger Sea. High-frequency observations of velocity, temperature and water vapour have been used to calculate turbulent fluxes of momentum, heat and moisture using the eddy covariance method. These are the first direct air-sea flux observations in this region, and add to the relatively small collection of direct air-sea flux observations made in high wind speed conditions. The aircraft-based turbulence legs were flown at remarkably low levels, only 30-50 m above the sea-surface and so within the atmospheric surface layer. Results are presented for 145 flux runs, each of $2 \mathrm{~min}$ (approximately $12 \mathrm{~km}$ ), 131 over open water and 14 over sea ice and the marginal ice zone. The flux data were obtained in $10 \mathrm{~m}$ neutral wind speeds of up to $25 \mathrm{~m} \mathrm{~s}^{-1}$, with $80 \%$ of the flux data in the range $15-19 \mathrm{~m} \mathrm{~s}^{-1}$.

Over open water, the wind stress varied from 0.2 to $1.9 \mathrm{~N} \mathrm{~m}^{-2}$ and the surface sensible and latent heat fluxes from 50 to $300 \mathrm{~W} \mathrm{~m}^{-2}$, resulting in total surface heat fluxes of up to $600 \mathrm{~W} \mathrm{~m}^{-2}$. The exchange coefficients are at the upper end of those previously observed. Mean values for the $15-19 \mathrm{~m} \mathrm{~s}^{-1}$ range are $C_{\mathrm{DN}}=2.04 \times 10^{-3}, C_{\mathrm{HN}}=1.63 \times 10^{-3}$ and $C_{\mathrm{EN}}=1.57 \times 10^{-3}$ for momentum, heat and moisture, respectively. The value of the momentum exchange coefficient is in line with previous studies; however, both the heat and moisture exchange coefficients are higher than in previous studies. Values of $C_{\mathrm{DN}}$ over sea ice and the marginal ice zone were in the range $1.67-6.29 \times 10^{-3}$ and were, for these conditions, generally higher than $C_{\mathrm{DN}}$ over adjacent open water areas. No significant spatial patterns in the exchange coefficients over open water have been detected, although there is some suggestion of higher exchange coefficients immediately downwind of the sea ice. Copyright (c) 2009 Royal Meteorological Society
\end{abstract}

KEY WORDS Greenland Flow Distortion experiment (GFDex); surface fluxes; eddy covariance fluxes; FAAM

Received 1 May 2008; Revised 3 November 2008; Accepted 4 November 2008

\section{Introduction}

Fluxes of momentum, heat and moisture between the ocean and atmosphere are important to both synopticscale weather systems and the climate system. For example, in tropical regions the heat stored in the ocean is the primary source of energy for hurricanes, while simultaneously the wind drag at the surface is their primary energy sink (French et al., 2007). Large air-sea fluxes are also a necessary condition for deep open-ocean convection, together with sufficient ocean preconditioning and a closed cyclonic circulation in the ocean (Marshall and Schott, 1999). Air-sea fluxes are therefore important for the overturning of the thermohaline circulation and thus the climate system. These conditions are only satisfied in a few regions in the oceans: the Labrador Sea, the Greenland-Iceland-Norwegian Seas, the Mediterranean Sea and the Weddell Sea (Killworth, 1983; Marshall and Schott, 1999). Lately, the Irminger Sea has been suggested as a region of convection and consequently deep water, previously thought to be formed solely in the

\footnotetext{
*Correspondence to: G. N. Petersen, School of Environmental Sciences, University of East Anglia, Norwich, NR4 7TJ, UK.

E-mail: g.n.petersen@uea.ac.uk
}

Labrador Sea, but which is now thought to be partly formed in the Irminger Sea (Pickart et al., 2003a; Pickart et al., 2003b). There has been a particular oceanographic interest in Denmark Strait for many years, as the main conduit of deep water out of the Nordic Seas and as the location of numerous major currents and jets (e.g. Bacon et al., 2002; Pickart et al., 2005).

Despite the obvious requirement for air-sea flux observations, accurate measurements in high wind speed conditions are relatively rare. There are only a few air-sea flux datasets in high winds in the extratropics: for example, early fixed-platform-based studies by Smith (1980) and Large and Pond (1981); the Humidity Exchange Over the Sea (HEXOS) programme, where data were collected from a fixed platform and instrumented aircraft over the North Sea for a wide range of wind speeds in fetch limited conditions (e.g. Smith et al., 1992; DeCosmo et al., 1996); ship-based observations over the Southern Ocean (e.g. Yelland and Taylor, 1996; Yelland et al., 1998); and more recent ship-based observations gathered as part of FASTEX (the Fronts and Atlantic Storm-Track Experiment; Eymard et al., 1999; Persson et al., 2005). Indeed, as noted in the recent review and update to the COARE 
bulk flux algorithm by Fairall et al. (2003), despite having over $7000 \mathrm{~h}$ of inertial dissipation and covariance flux observations in the National Oceanic and Atmospheric Administration (NOAA) Environmental Technology Laboratory (ETL) database, these include only 133 and $85 \mathrm{~h}$ of momentum and moisture flux data, respectively, for wind speeds greater than $15 \mathrm{~m} \mathrm{~s}^{-1}$.

One historical reason for the lack of eddy covariance flux data has been the technological challenges in making these eddy correlation types of calculation from a ship. The ship is moving with the sea-surface and is subject to ever-changing flow distortion effects. These difficulties have meant many ship-based studies have relied on the inertial dissipation method to estimate the exchange coefficients (e.g. Yelland and Taylor, 1996; Yelland et al., 1998; Eymard et al., 1999; Bumke et al., 2002). However, this method is less direct, relies on a choice of dimensionless dissipation function, is subject to flow distortion around the ship, and has recently been subject to some debate as to whether an imbalance term is required or not (e.g. Janssen, 1999; Taylor and Yelland, 2001). This makes the air-sea flux data reported by Persson et al. (2005) from ship-based observations during FASTEX especially valuable as they present both covariance and inertial dissipation fluxes. Indeed, Persson et al. (2005) claim that their study provides the first 'open-ocean covariance flux measurements in high wind ( $\left.U>15 \mathrm{~m} \mathrm{~s}^{-1}\right)$ conditions', here defining 'open ocean' to mean more than $\sim 100 \mathrm{~km}$ from the coast.

Lately, it has become more common to use an instrumented aircraft to make observations of air-sea fluxes. Using an aircraft has some advantages over using a ship: for example, the platform is independent of the seasurface and flow distortion effects should be more uniform for any particular run. Of course, aircraft-based flux calculations bring their own disadvantages: for example, the quantity of data is much lower and runs must be carefully chosen to maintain homogeneous conditions. During the Southern Ocean Waves Experiment (SOWEX), 29 runs of eddy covariance fluxes were estimated in a broad range of wind speeds in fetch unlimited conditions (Banner et al., 1999). Recently, as part of the Coupled Boundary Layer Air-Sea Transfer (CBLAST) programme (Black et al., 2007), French et al. (2007) and Drennan et al. (2007) have presented covariance fluxes of momentum and moisture, respectively, in extremely high wind speed conditions within the hurricane boundary layer. However, such studies over the open ocean are still relatively rare, especially for high wind speed conditions.

One of the main goals of the Greenland Flow Distortion experiment (GFDex) was to obtain observations of air-sea fluxes of momentum, heat and moisture over Denmark Strait and the Irminger Sea, associated with the high wind speed events that occur when flow impinges upon Greenland. The eddy covariance flux estimates obtained during the GFDex were over the open ocean during cold-air outbreaks, and generally with $10 \mathrm{~m}$ winds in excess of $15 \mathrm{~m} \mathrm{~s}^{-1}$. Consequently, the air-sea fluxes were generally high, with heat fluxes of up to $300 \mathrm{~W} \mathrm{~m}^{-2}$ at times. We present data from over 100 turbulence runs acquired at an average height of $39 \mathrm{~m}$ above the seasurface. These represent the only aircraft-based direct flux measurements over this part of the North Atlantic. Not only are the data of importance for atmospheric and oceanographic research in the region, but the data are also a valuable addition to the existing surface flux data repository.

The article is organized as follows. In section 2, we summarize the theory of direct covariance flux calculations and bulk flux calculations. We introduce the GFDex and the missions with low-level data in section 3 , and give a detailed description of the aircraft measurements in section 4 . We explain the quality control procedure in section 5, and give the results in section 6 . In section 7 we provide a discussion and some concluding remarks.

\section{Theory}

The eddy covariance flux method uses high-frequency measurements of the wind velocity components, temperature and humidity to estimate the turbulent wind stress or momentum flux, $\tau$, sensible heat, $S H$, and latent heat flux, $L H$, over a defined time interval or run:

$$
\begin{aligned}
\tau & =\bar{\rho} \sqrt{\overline{u^{\prime} w^{\prime}}+\overline{v^{\prime} w^{\prime}}} \\
S H & =\bar{\rho} c_{\mathrm{p}} \overline{w^{\prime} \theta^{\prime}} \\
L H & =\bar{\rho} L_{\mathrm{v}} \overline{w^{\prime} q^{\prime}} \\
\bar{\rho} & =\frac{\bar{p}}{R \overline{\theta_{\mathrm{v}}}} .
\end{aligned}
$$

Here $u^{\prime}, v^{\prime}, w^{\prime}, \theta^{\prime}$ and $q^{\prime}$ are perturbations of the three wind components, potential temperature and humidity from the run average, where $\theta=T+\gamma z$ is a function of the air temperature $T$ and the altitude $z \cdot \bar{\rho}$ is the run average air density, and similarly $\bar{p}$ and $\overline{\theta_{\mathrm{v}}}$ are the run average air pressure and virtual potential temperature, respectively. $c_{\mathrm{p}}=1004 \mathrm{~J} \mathrm{~kg}^{-1} \mathrm{~K}^{-1}$ is the specific heat for dry air, $L_{\mathrm{v}}=2.5 \times 10^{6} \mathrm{~J} \mathrm{~kg}^{-1} \mathrm{~K}^{-1}$ is the latent heat of vaporization, $R=287 \mathrm{~J} \mathrm{~kg}^{-1} \mathrm{~K}^{-1}$ is the gas constant for dry air and $\gamma=0.00975 \mathrm{~K} \mathrm{~m}^{-1}$ is the adiabatic lapse rate.

In making turbulence measurements there is a systematic underestimation of the surface wind stress due to the assumption of a constant stress layer in the lower boundary layer (Donelan, 1990; Banner et al., 1999; French et al., 2007). This bias can be corrected for by taking into account the influence of the Coriolis force and the horizontal pressure gradient. The correction assumes the following: (1) at the surface, there is a balance between the wind stress gradient and the horizontal pressure gradient; (2) the wind stress decays with height in the atmospheric boundary layer (ABL); (3) the wind stress vanishes at the top of the marine ABL where there is a geostrophic balance. Furthermore, the conditions must be temporally and spatially homogeneous (Donelan, 1990). This results 
in

$$
\frac{\tau}{\bar{\rho}}=u_{*}^{2}=u_{* \mathrm{~s}}^{2}\left(1-\frac{\alpha_{0} f z}{u_{* \mathrm{~s}}}\right),
$$

where $u_{*}$ is the friction velocity and $f$ is the Coriolis parameter. $\alpha_{0}=\left|V_{\mathrm{gs}} / u_{* \mathrm{~s}}\right|$ is a constant, where $V_{\mathrm{gs}}$ is the component of the geostrophic wind normal to the surface winds. The subscript ' $\mathrm{s}$ ' denotes atmospheric values at the surface. The conditions above are assumed to be fulfilled for the GFDex data and it is therefore plausible to apply this correction. Following Donelan (1990), we apply $\alpha_{0}=12$, which is the value for neutral conditions. In the rest of this article, the correction is applied for the wind stress but for simplicity the subscript ' $s$ ' is omitted. For the GFDex data, where measurement heights are $30-50 \mathrm{~m}$ above the sea, this correction is typically about $8 \%$ for the wind stress.

As direct measurements of surface fluxes are not always available, it is often necessary to estimate the fluxes from more standard data. The fluxes of momentum, heat and moisture are assumed to be approximately constant in the atmospheric surface layer and the mean profiles of wind speed, temperature and specific humidity to increase logarithmically with height above the surface in the case of neutral stratification (e.g. Businger, 1982; DeCosmo et al., 1996). Empirical relationships have been derived to take into account deviations from neutral stratification resulting in the following equations:

$$
\begin{aligned}
U(z)-U_{\mathrm{s}} & =\frac{u_{*}}{k}\left\{\ln \left(\frac{z}{z_{o}}\right)-\Psi_{m}\right\} \\
\theta(z)-\theta_{\mathrm{s}} & =\frac{\operatorname{Pr} \theta_{*}}{k}\left\{\ln \left(\frac{z}{z_{o t}}\right)-\Psi_{t}\right\} \\
q(z)-q_{\mathrm{s}} & =\frac{\operatorname{Pr} q_{*}}{k}\left\{\ln \left(\frac{z}{z_{o q}}\right)-\Psi_{q}\right\} .
\end{aligned}
$$

Here, $U(z), \theta(z)$ and $q(z)$ are the horizontal wind speed, potential temperature and specific humidity at height $z$, respectively. Again, the subscript 's' denotes atmospheric values at the surface. The surface wind speed is usually assumed to be negligible, while $\theta_{\mathrm{s}}$ is the seasurface potential temperature and the humidity at the surface, $q_{\mathrm{s}}$, is calculated from the sea-surface temperature (SST), assuming 98\% saturation due to salinity effects (Fairall et al., 2003). $\theta_{*}$ and $q_{*}$ are the temperature and humidity scaling parameters, while $z_{o}, z_{o t}, z_{o q}$ are surface roughness lengths for wind speed, temperature and humidity, respectively. $k=0.4$ is the von Karman constant and $\mathrm{Pr}$ is the Prandtl number. We have used $\operatorname{Pr}=1.0$, which is consistent with the majority of the literature (e.g. DeCosmo et al., 1996; Fairall et al., 2003; Brunke et al., 2006). $\Psi_{m}, \Psi_{t}$ and $\Psi_{q}$ are the empirical stability functions. In the current study, we have applied the Dyer (1974) stability terms for stable conditions and the Paulson (1970) terms for unstable conditions, estimating the stability with the Monin-Obukhov length (Stull, 1988):

$$
L=\frac{\overline{\theta_{\mathrm{v}}} u_{*}^{2}}{k g \theta_{*}} .
$$

Here, $\overline{\theta_{\mathrm{v}}}$ is the run average virtual potential temperature and $g=9.81 \mathrm{~m} \mathrm{~s}^{-2}$ is the gravitational acceleration. For stable conditions $(z / L>0)$

$$
\Psi_{m}=\Psi_{t}=\Psi_{q}=-\frac{\beta z}{L},
$$

where $\beta=5$, as in Smith (1988). For unstable conditions $(z / L<0)$

$$
\begin{gathered}
\Psi_{m}=2 \ln \left(\frac{1+x}{2}\right)+\ln \left(\frac{1+x^{2}}{2}\right)-2 \arctan x+\frac{\pi}{2} \\
\Psi_{t}=\Psi_{q}=2 \ln \left(\frac{1+x^{2}}{2}\right)
\end{gathered}
$$

where

$$
x=(1-16 z / L)^{1 / 4}
$$

The surface fluxes can be calculated using bulk formulations:

$$
\begin{aligned}
\tau & =\bar{\rho} C_{\mathrm{DN}}\left(U_{10 \mathrm{~N}}-U_{\mathrm{s}}\right)^{2} \\
S H & =\bar{\rho} c_{\mathrm{p}} C_{\mathrm{HN}}\left(U_{10 \mathrm{~N}}-U_{\mathrm{s}}\right)\left(\theta_{\mathrm{s}}-\theta_{10 \mathrm{~N}}\right) \\
L H & =\bar{\rho} L_{\mathrm{v}} C_{\mathrm{EN}}\left(U_{10 \mathrm{~N}}-U_{\mathrm{s}}\right)\left(q_{\mathrm{s}}-q_{10 \mathrm{~N}}\right)
\end{aligned}
$$

Here, $U_{10 \mathrm{~N}}, \theta_{10 \mathrm{~N}}$ and $q_{10 \mathrm{~N}}$ are the values at the $10 \mathrm{~m}$ neutral reference height, for example $U_{10 \mathrm{~N}}=u_{*} / k \ln \left(10 / z_{0}\right)$.

Similarly, $C_{\mathrm{DN}}, C_{\mathrm{HN}}$ and $C_{\mathrm{EN}}$ are the $10 \mathrm{~m}$ neutral exchange coefficients for momentum, heat and moisture, respectively. The exchange coefficients are evaluated through laboratory and field experiments, usually through evaluation of the surface roughness lengths. By combining and rearranging (14)-(16) and (6)-(8), and using $\tau / \rho=u_{*}^{2}$, we obtain

$$
\begin{aligned}
C_{\mathrm{DN}} & =\left(\frac{u_{*}}{U_{10 \mathrm{~N}}}\right)^{2}=\frac{k^{2}}{\ln \left(10 / z_{o}\right)^{2}} \\
C_{\mathrm{HN}} & =\frac{k^{2}}{\operatorname{Pr} \ln \left(10 / z_{o}\right) \ln \left(10 / z_{o t}\right)} \\
C_{\mathrm{EN}} & =\frac{k^{2}}{\operatorname{Pr} \ln \left(10 / z_{o}\right) \ln \left(10 / z_{o q}\right)} .
\end{aligned}
$$

Note that Donelan (1990) and Drennan et al. (2007) use a different Prandtl number in their calculations, $\operatorname{Pr}=0.85$. However, as the Prandtl number is present in both (7)-(8) and (18)-(19) the effect on the exchange coefficients is negligible.

\section{The Greenland Flow Distortion experiment}

The GFDex is an international project investigating the role of Greenland in defining the structure and predictability of both local and downstream weather systems. The field campaign was primarily aircraft-based, 
utilizing the specially instrumented Facility for Airborne Atmospheric Measurements (FAAM) BAE 146 aircraft. An overview of the experiment can be found in Renfrew et al. (2008). One of the goals of the field campaign was to obtain estimates of air-sea fluxes of momentum, heat and moisture. The following six of the 12 GFDex missions included low-level flight legs at 'minimum safe altitude', approximately $30-50 \mathrm{~m}$ above the sea.

B268: A reverse or easterly tip jet mission at Cape Farewell on 21 February 2007. The wind speed at flight level was $20-33 \mathrm{~m} \mathrm{~s}^{-1}$. There were cloudy conditions and some precipitation. All low-level legs were over open water.

B271: A polar mesoscale cyclone mission near Jan Mayen on 25 February 2007. Close to the ice edge, the skies were clear and the wind speed $\sim 5 \mathrm{~m} \mathrm{~s}^{-1}$. To the east, the wind increased to $16-20 \mathrm{~m} \mathrm{~s}^{-1}$ and at the eastern end of the low-level flight leg, the cloud cover increased.

B274: A barrier wind mission in Denmark Strait on 2 March 2007. All low-level flight legs were over open water, with wind speed at flight level $20-30 \mathrm{~m} \mathrm{~s}^{-1}$ in cloudy conditions.

B276: A barrier wind mission south of Denmark Strait on 5 March 2007. The mission was partly over the marginal ice zone (MIZ) or sea ice, where the wind speed was $\sim 10 \mathrm{~m} \mathrm{~s}^{-1}$ and the skies clear. Over the open water, the wind speed was $\sim 20 \mathrm{~m} \mathrm{~s}^{-1}$ with scattered or broken clouds.
B277: A barrier wind mission in Denmark Strait on 6 March 2007. The low-level leg was over open water in flight level wind speed of $20-30 \mathrm{~m} \mathrm{~s}^{-1}$ and cloudy conditions.

B278: A Lagrangian surface flux mission in Denmark Strait on 9 March 2007. The mission was over open water downwind of the sea-ice zone. The wind speed was $\sim 15-20 \mathrm{~m} \mathrm{~s}^{-1}$, and the clouds scattered to broken. There was slight precipitation during two of the low-level flight legs.

There are no in situ measurements of wave height. The extratropical North Atlantic is climatologically a region of generally high waves, with a mean significant wave height exceeding $4 \mathrm{~m}$ in the Irminger Sea (Woolf et al., 2002). We estimate that in the more extreme wind cases (B268, B274 and B277) the significant wave heights were 5-10 m. Figure 1 shows the flight tracks of the missions above with the low-level flight legs in bold. Unfortunately, some of the high-frequency data from two of the flights (B268 and B274) are missing. In the reverse tip jet mission (B268), the low-level legs were flown at the end of the science flight. While descending through the clouds, down to $\sim 40 \mathrm{~m}$ above the sea, wetting of the temperature sensors occurred, resulting in the dynamic heating being approximately as predicted by wet adiabatic processes. The high-frequency temperature measurements are therefore invalid during the low-level flight legs of this mission. However, as dropsonde observations during the mission show that the boundary layer was almost neutral and thus the stability correction (11) was

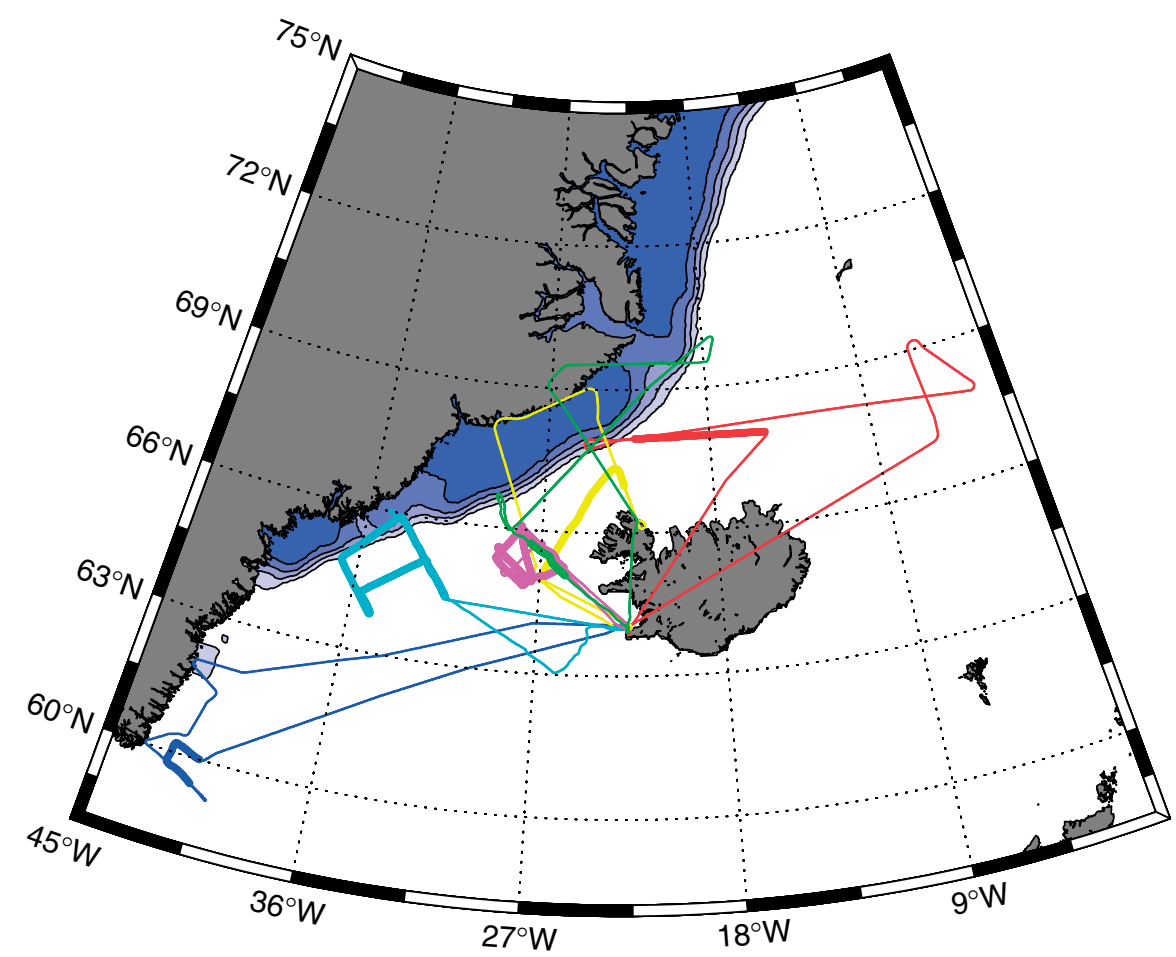

Figure 1. Flight tracks of the GFDex missions with low-level flight legs. The flight tracks are shown with thin lines and the low-level flight legs with bold lines: blue, B268; red, B271; yellow, B274; cyan, B276; green, B277; magenta, B278. The sea-ice concentration on 5 March is shown in shading, with contour interval 0.2 . 
small, we have included the momentum flux for B268. Similarly, the low-level flight legs of B274 were flown after the structure of the barrier flow had been observed using dropsondes. During the descent, ice formed on the aircraft radome (the 'nose' of the aircraft) where the five-port pressure measurement system, which is vital for high-frequency wind velocity measurements, is located. Occasionally, when this type of icing occurs it can be removed by using in-flight manoeuvres. However, during the GFDex the air temperature was too low for any such manoeuvres to be helpful. Therefore, no turbulence probe measurements are available during B274 and thus no eddy covariance flux estimates. However, as it was possible to derive $1 \mathrm{~Hz}$ horizontal wind components from the Inertial Navigation Unit (INU) measurements, bulk flux calculations can be made.

During the missions with available low-level highfrequency data, the marine surface layer was slightly unstable with at flight level the average stability parameter $z / L=-0.22$. For flux estimates, each low-level flight leg is divided into a number of flux runs, each 2 min long. Table I summarizes the missions in terms of low-level flight legs and the number of flux runs.

\section{Aircraft measurements}

The FAAM BAE 146 is a mid-size four-engine modified passenger jet with an endurance of up to $6 \mathrm{~h}$ and a working altitude range of 100 to 30000 feet. All the turbulence flux runs analysed here were flown at 'minimum safe altitude' (i.e. in the range $30-50 \mathrm{~m}$ ), and at a standard science speed of 200 knots indicated air speed $\left(\sim 100 \mathrm{~m} \mathrm{~s}^{-1}\right)$. The average run altitudes for each flight are shown in Table I. Although a relatively new facility (operational from 2004), the majority of the FAAM instrumentation was transferred over from the UK's previous large-scale aircraft facility, the UK Met Office's Hercules (C-130). This means that instrument performance, quality and history are reasonably well known (e.g. Nicholls, 1978; Brown et al., 1983; Inverarity, 2000). A summary of the aircraft's 'core' instrumentation is presented in Renfrew et al. (2008). In the rest of this section, we describe the instrumentation and data quality for the key measurements required to calculate covariance fluxes.

\subsection{Wind and pressure measurements}

The turbulence probe of the FAAM aircraft consists of a five-port pressure measurement system in the aircraft radome and two scientific static ports, symmetrically placed on either side of the aircraft, and it follows principles described by Brown et al. (1983). The system also utilizes measurements from the reduced vertical separation minimum (RVSM)-compliant air data computer and science measurements of the ambient air temperature, corrected for kinetic effects via an iteration routine. The outputs from the turbulence probes (the angles of attack, the sideslip and the true air speed) are then used in conjunction with the Kalman-filtered INU measurements of aircraft altitude and aircraft velocity components to derive northwards, eastwards and vertical components of wind velocity, which is recorded at $32 \mathrm{~Hz}$. Pressure altitude is recorded from the RVSM system and inverted to give static pressure, also at $32 \mathrm{~Hz}$.

Occasional turbulence probe calibration flights are undertaken with the results postprocessed to minimize vertical wind variance (P. R. A. Brown, personal communication). One such calibration flight (B263) was undertaken by the Met Office immediately prior to the GFDex

Table I. Summary of low-level flight legs, total time at low levels, number of low-level flight legs during mission, total number of flux runs and comments regarding runs used in flux calculations.

\begin{tabular}{|c|c|c|c|c|c|}
\hline Mission & Time $(\min )$ & No of legs & No of runs & Mean altitude (m) & Comments \\
\hline B268 & 31 & 3 & 14 & 43 & $\begin{array}{l}\text { Calibrated OSTIA SST used; three runs } \\
\text { discarded in quality control (QC; } \\
\text { see section 5) of } \overline{u^{\prime} w^{\prime}} \text {; all runs discarded } \\
\text { in QC of } \overline{q^{\prime} w^{\prime}} \text {; all runs discarded } \\
\text { for sensible heat flux due to wetting of } \\
\text { temperature sensors }\end{array}$ \\
\hline B271 & 46 & 1 & 22 & 43 & $\begin{array}{l}\text { Calibrated OSTIA SST used; one run } \\
\text { discarded in QC of } \frac{u^{\prime} w^{\prime}}{}\end{array}$ \\
\hline B274 & 43 & 2 & 20 & 43 & $\begin{array}{l}\text { All runs discarded; no high-frequency } \\
\text { wind data }\end{array}$ \\
\hline B276 & 138 & 6 & 62 & 36 & $\begin{array}{l}\text { One run discarded in } \mathrm{QC} \text { of } \overline{u^{\prime} w^{\prime}} \text {; five } \\
\text { runs discarded in } \mathrm{QC} \text { of } \overline{T^{\prime} w^{\prime}}\end{array}$ \\
\hline B277 & 17 & 1 & 8 & 38 & $\begin{array}{l}\text { Three runs discarded for latent heat flux } \\
\text { due to the presence of liquid water }\end{array}$ \\
\hline B278 & 90 & 6 & 39 & 38 & $\begin{array}{l}\text { Seven runs discarded in } \mathrm{QC} \text { of } \overline{u^{\prime} w^{\prime}} \text {; } \\
\text { three runs discarded in } \mathrm{QC} \text { of } \overline{q^{\prime} w^{\prime}} ; \\
\text { one run discarded for latent heat flux due } \\
\text { to the presence of liquid water }\end{array}$ \\
\hline
\end{tabular}


and with the same aircraft fit. The B263 flight pattern consisted of (1) pairs of straight and level runs on opposite headings, which were used to calculate a factor for the true air speed calibrations, and (2) yawing (side to side) oscillations during turns to check the angles of attack and sideslip measurements and the offset angles of the INU relative to the aircraft axes in the pitch and roll planes. Errors in all four of these parameters can contribute erroneous vertical wind signals that are correlated with the manoeuvres. The data from (2) were processed using a scheme that minimizes vertical wind variance (A. R. Rodi, personal communication). The correction factors were then applied when processing the final output datasets. The results from this flight suggest that, on average, the horizontal wind measurement uncertainties will be $<0.27 \mathrm{~m} \mathrm{~s}^{-1}$. Overall, the uncertainty in horizontal wind measurements is estimated to be $< \pm 0.5 \mathrm{~m} \mathrm{~s}^{-1}$, with relative errors $<0.1 \mathrm{~m} \mathrm{~s}^{-1}$. The estimated absolute accuracy in static pressure is estimated to be of the order of $0.5 \mathrm{hPa}$.

Further validation of the FAAM turbulence system is provided by an aircraft intercomparison flight, with the National Center for Atmospheric Research (NCAR) C130, during mission B079 on 23 January 2005 as part of the Rain in Cumulus over Oceans (RICO) campaign (Rauber et al., 2007). Data from a 30 min side-by-side intercomparison in clear air at $\sim 400 \mathrm{~m}$ over the ocean have been examined. The aircraft were sampling welldeveloped ABL turbulence (e.g. the standard deviation of horizontal velocity was $\sim 0.5 \mathrm{~m} \mathrm{~s}^{-1}$ for a run mean wind speed of $\sim 7 \mathrm{~m} \mathrm{~s}^{-1}$ ). Although one would obviously not expect an exact correspondence in wind velocities (the aircraft displacement means they were not actually sampling the same eddies), one would expect similar turbulence statistics. Examination of power spectra and probability density functions (pdfs) of perturbation velocities and temperature shows that this is indeed the case. The power spectra correspond well and both show the expected $-5 / 3$ power-law decay. The normalized pdfs have the same shape and are typically within $0.1 \mathrm{~m} \mathrm{~s}^{-1}$ (or $0.01 \mathrm{~K}$ ) of each other, indicating a similar instrument response to the observed turbulence.

\subsection{Temperature measurements}

The air temperature is measured with Rosemount temperature sensors using de-iced (Rosemount 102BL) and nonde-iced (Rosemount 102AL) platinum resistance immersion thermometers with type-b housings. During all available GFDex low-level flights, the non-de-iced sensor remained ice-free and the data from this sensor are therefore used in all calculations. The instrument has an overall measurement uncertainty of $\pm 0.3^{\circ} \mathrm{C}$ at $95 \%$ confidence for a typical clear air measurement and relative errors $<0.01^{\circ} \mathrm{C}$. The measurements are recorded at $32 \mathrm{~Hz}$. However, as a result of the sensor being enclosed by a protective housing, a time-lag and damping of the temperature measurements are induced. It is therefore necessary to postprocess the data to compute the true high-frequency air temperature from the indicated air temperature. Following Inverarity (2000), we have lowpass filtered the measurements, using a single-pole recursive filter, to avoid amplifying noise when applying a frequency correction. We have then corrected the temperature using the algorithm of McCarthy (1973). The algorithm improves the response in the range $0.1-7 \mathrm{~Hz}$ and is close to unity up to $1 \mathrm{~Hz}$. At frequencies higher than $7 \mathrm{~Hz}$, the response falls off rapidly below that of the measured signal. However, as this frequency range accounts for turbulence of scale smaller than $20 \mathrm{~m}$, it is unlikely to contribute much to the energy transfer.

The temperature sensor is located about $2 \mathrm{~m}$ from the nose of the aircraft, so the estimated time-lag at the indicated air speed of $100 \mathrm{~m} \mathrm{~s}^{-1}$ is $1 / 50 \mathrm{~s}$. This is less than the reported frequency of the measurement and we have therefore not lagged the temperature time series.

\subsection{Sea surface temperature measurements}

A Heimann radiometer measures the upwelling infrared radiance in the range $8-14 \mu \mathrm{m}$ and records at $4 \mathrm{~Hz}$. Below cloud base, the measurement is a function of the surface temperature, $T_{\mathrm{s}}$, according to

$$
R_{\lambda}^{\uparrow}=\epsilon_{\lambda} B_{\lambda}\left(T_{\mathrm{s}}\right)+\left(1-\epsilon_{\lambda}\right) R_{\lambda}^{\downarrow} .
$$

Here, $R_{\lambda}^{\uparrow}$ is the upwelling radiance (applicable for the Heimann radiometer with its $4^{\circ}$ field of view) at wavelength $\lambda$. The first term on the right-hand side is the product of sea-surface emissivity, $\epsilon_{\lambda}$, and the Planck emission, $B_{\lambda}$, at temperature $T_{\mathrm{s}}$, while the second term is the reflected component of the downwelling radiance, $R_{\lambda}^{\downarrow}$. For instruments such as the Heimann radiometer, the emissivity is often estimated as $\epsilon_{\lambda}=0.987$ (Niclós et al., 2005; Masuda et al., 1988). To a first approximation, the second term in (20) may be neglected, while an emissivity correction is applied to the measured Heimann radiance so that the derived brightness temperature may be related to the sea surface temperature (SST), within a specified accuracy of $0.7 \mathrm{~K}$.

The Heimann radiometer needs to be calibrated over open water at the start of each low-level flight. During B276, two calibrations were made, as it was found necessary to calibrate the sensor again after flying over sea ice. Figure 2 shows the upwelling brightness temperature measured during the low-level flight legs of B276. The bold vertical lines, at 12:38 and 13:34, represent the two calibrations. It is clear from the temperature that the second calibration was carried out too early, as further sea ice was encountered. Also, the start and the end of the low-level flight were along the same line and the measured $T_{\mathrm{B}}$ should therefore have been the same. To correct for this bias, the upwelling brightness temperature over open water after crossing the sea ice is corrected by $0.8 \mathrm{~K}$.

The brightness temperature measurements are not available for B271, the polar cyclone mission. The SST applied instead is from the Operational Sea Surface Temperature and Sea Ice Analysis (OSTIA) dataset, which has been developed by the UK Met Office (http://ghrsstpp.metoffice.com/pages/latest_analysis/ostia.html). The 


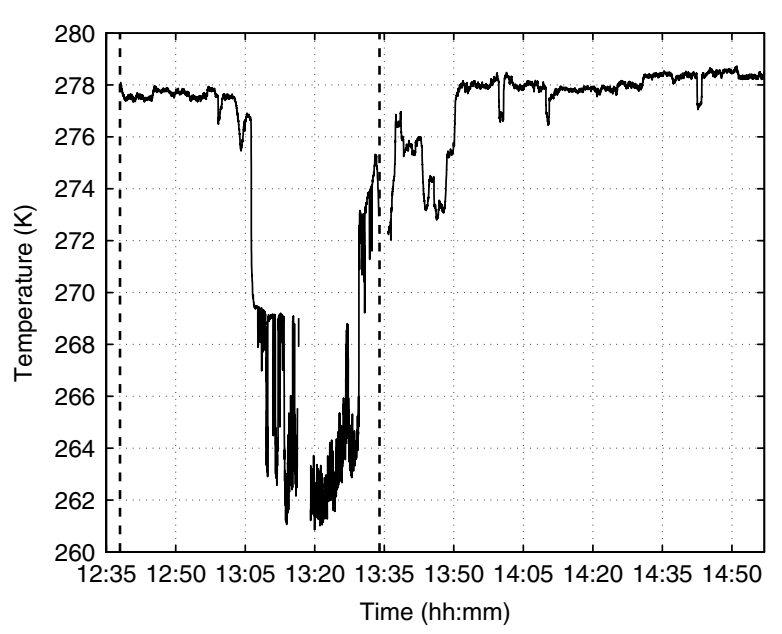

Figure 2. Upwelling brightness temperature $(\mathrm{K})$ during the low-level flight legs of B276, 5 March 2007, as a function of time. The two bold, dashed vertical lines represent the timing of the Heimann radiometer calibrations.

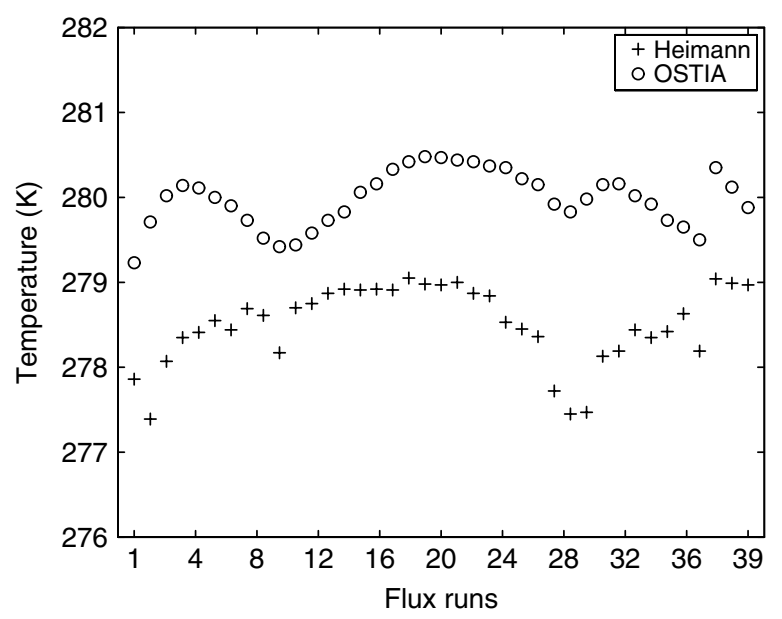

Figure 3. Flux run average Heimann upwelling (crosses) and OSTIA (circles) SST (K) for the flux runs of B278, 9 March 2007.

output is a daily, global coverage $1 / 20^{\circ}(\sim 6 \mathrm{~km})$ combined SST and sea-ice concentration product, which is generated in near-real time. The analysis is designed to provide an accurate SST, suitable for numerical weather prediction at global and regional space and time-scales. Further description of the OSTIA dataset can be found in Stark et al. (2007). We compared the OSTIA SST to the Heimann upwelling temperature for B276, B277 and B278. The comparison showed there to be a systematic bias between the two datasets with the OSTIA SST $1.5 \mathrm{~K}$ higher than the Heimann $T_{\mathrm{B}}$ (see Figure 3 ). This systematic bias can also be seen in a comparison of the OSTIA SST with, for example, ECMWF analysis (Renfrew et al., 2009). For consistency, the OSTIA SST applied in the case of B271 is therefore corrected for this $1.5 \mathrm{~K}$ bias before it is used in the flux calculations.

\subsection{Humidity measurements}

In order to calculate the latent heat fluxes by the eddy covariance method, it is necessary to have high-frequency measurements of water vapour. The instrument available is a Lyman- $\alpha$ absorption hygrometer, which records total water at $64 \mathrm{~Hz}$ with an uncertainty in the measurements of $\pm 0.15 \mathrm{~g} \mathrm{~kg}^{-1}$ (Nicholls et al., 1990). The instrument response changes with time because of the degradation of the absorption windows that allow the radiation into the sample volume. To estimate this drift, measurements are compared to humidity measurements made in clear air by the General Eastern instrument, a hygrometer recording at $4 \mathrm{~Hz}$. The Lyman- $\alpha$ data are postprocessed by comparing profiles at the start and end of the flight and because the drift in the Lyman- $\alpha$ instrument is quite linear with time, these two calibrations can then be used to interpolate throughout the flight (Nicholls et al., 1990).

The Lyman- $\alpha$ sensor is also located $2 \mathrm{~m}$ from the nose of the aircraft and the estimated time difference between measurements of the wind components and the total water is therefore also $1 / 50 \mathrm{~s}$. The reporting frequency is $64 \mathrm{~Hz}$, and so a lag of the humidity time series by one sample, 1/64 s, takes account of this time difference. Sensitivity tests show that this results in a $2 \%$ increase in the moisture exchange coefficient.

As the hygrometer measures total water (i.e. water vapour plus liquid water), it is clear that when there is liquid water in the air the data cannot be used for latent heat flux estimates. These incidents are identified using the liquid water content measurements from a Johnson-Williams probe. The Johnson-Williams probe measures the concentration of liquid water in the air using a heated wire resistance bridge. Experience at FAAM has shown that it is a reliable, robust device. However, the instrument compensation arrangement on the FAAM aircraft introduces a drift in the instrument baseline response under flight conditions. By identifying deviations from the (drifting) base line of the Johnson-Williams liquid water measurements, encounters with liquid water can be identified and the corresponding data discarded from the Lyman- $\alpha$ measurements. Fortunately, there were few such incidents of liquid water at flight level during the GFDex low-level flight legs, and the events were easily identified manually. Figure 4 shows the total water and the liquid water during B278, low-level flight leg 5, with the three incidents of liquid water shaded. Runs where liquid water was present were rejected, resulting in three runs rejected from B277 and one from B278.

\subsection{Altitude measurements}

The flight level altitude used in the calculations of the exchange coefficients is the average radar altitude of the aircraft. The radar altimeter records at $2 \mathrm{~Hz}$ and has an uncertainty of $\pm 2 \%$ below $760 \mathrm{~m}(2500 \mathrm{ft})$, that is, at $40 \mathrm{~m}$ the uncertainty is $< \pm 1 \mathrm{~m}$. The low-level measurements were carried out at $32-51 \mathrm{~m}$ radar altitude above the sea with an average altitude of $39 \mathrm{~m}$. The standard deviation of the run altitude varies between 1.6 and $7.8 \mathrm{~m}$ with a mean standard deviation of $3.5 \mathrm{~m}$. 
(a)

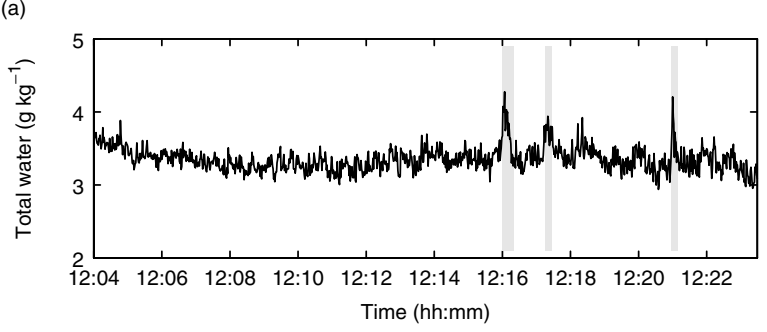

(b)

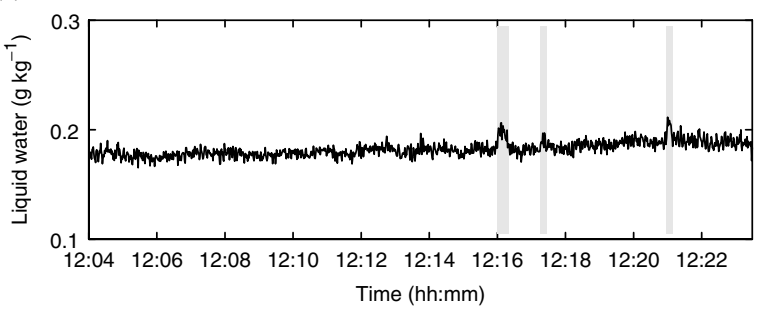

Figure 4. (a) Total water measured by the Lyman- $\alpha$ hygrometer $\left(\mathrm{g} \mathrm{kg}^{-1}\right)$ and (b) liquid water measured by the Johnson-Williams probe $\left(\mathrm{g} \mathrm{kg}^{-1}\right)$ measured during B278, 9 March 2007. The shaded areas represent incidents of liquid water.

\subsection{Flux calculation procedure}

Each flux run should sample homogeneous data (i.e. the atmosphere and the surface should be homogeneous and aircraft motion changes should be minimal). The surface is divided into two categories: open water and sea ice. The sea-ice category includes all runs where there is the possibility of sea ice.

Most of the low-level flights were over open water, 131 runs out of a total of 145 . There are large uncertainties in the brightness temperature measurements in areas with sea ice, as the surface can be an inhomogeneous mixture of sea ice and water. It is therefore not possible from our data to obtain any significant results for air-sea fluxes over sea ice. However, in order not to disregard these data entirely, the measurements over ice and MIZ are shown where appropriate, but it must be noted that there is much uncertainty in any calculations over regions with sea ice.

Each run should include several wavelengths of the flux transport process in question. In this study, we are concerned about ABL turbulence, which is of a length-scale similar to the ABL height. For every flight, dropsonde data are available, from which the ABL height can be determined from the gradient of the potential temperature to be $\sim 1-2 \mathrm{~km}$. The run length is motivated by the need for runs to be long enough to cover several wavelengths of the turbulence but at the same time short enough to provide sampling over a homogeneous surface. This is especially important as the observations are often made close to the heterogeneous ice edge and ocean SST fronts. Hence, we choose to divide the flight legs into runs of $2 \mathrm{~min}$, or approximately $12 \mathrm{~km}$. The last run of each flight leg includes the remainder of the flight leg, resulting in a few runs longer than $2 \mathrm{~min}$, the longest $3 \mathrm{~min} 55 \mathrm{~s}$. In total, there are 131 flux runs at typical altitudes of 30-50 $\mathrm{m}$ above the sea-surface.
The turbulent flux calculations are computed at $32 \mathrm{~Hz}$. The $64 \mathrm{~Hz}$ humidity measurements are resampled to $32 \mathrm{~Hz}$ while the $2 \mathrm{~Hz}$ altitude measurements are interpolated to $32 \mathrm{~Hz}$. The turbulent altitude measurements are important for the potential temperature but because of the low frequency of the measurements, little variation is added to the turbulent potential temperature. All turbulent variables are linearly detrended within the flux run before the air-sea fluxes of momentum, heat and moisture are calculated using (1)-(3).

\section{Quality control}

Each flux run has to pass a strict data quality check (French et al., 2007) including inspection of the following.

- The power spectra of the along-wind velocity component, temperature and water vapour. In the inertial subrange, the spectra should have a welldefined power-law decay slope of $-5 / 3$ with wavenumber. The cross-wind velocity component is much smaller than the along-wind, it contains little energy and its power spectra are therefore of little importance.

- The linear cumulative summation of the covariances of the vertical velocity and along-wind velocity, temperature and water vapour. The cumulative summation should have a near constant slope over the entire run.

- The cospectra of the covariances should have no power at wavenumber smaller than about $10^{-4}$ $\mathrm{m}^{-1}$ as power at such wavenumbers would suggest energy associated with mesoscale features, instead of only turbulence.

- The ogives, the cumulative summation of the cospectra, should have an S-shaped curve with flat ends.

Figure 5 shows examples of quality control graphs for the along-wind component of two runs, a good run and a discarded run. The top panel shows the linear cumulative summation of the covariances, the centre panel the cospectra and the bottom panel the ogives. The along-wind covariance of the discarded run fails all three tests. There are disturbances in the cumulative summation of the covariance over most of the discarded run and the ogives diverge greatly from the expected S-shape. For the good run, the cumulative summation has a near constant slope over the whole run. The ogives have the expected S-shape and the cospectra suggest that the majority of the energy in the momentum flux is from eddies ranging from 90 to $800 \mathrm{~m}$ in size. Note that this fact justifies the length of our runs, as runs of $2 \mathrm{~min}$, or $\sim 12 \mathrm{~km}$, can sample a multiple of eddies of these scales.

Most of the flux runs passed the quality control check (see Table I). Of the total of 131 flux runs over open water, 120 were accepted for wind stress calculations, 109 for sensible heat flux calculations and 102 for latent heat flux calculations. 

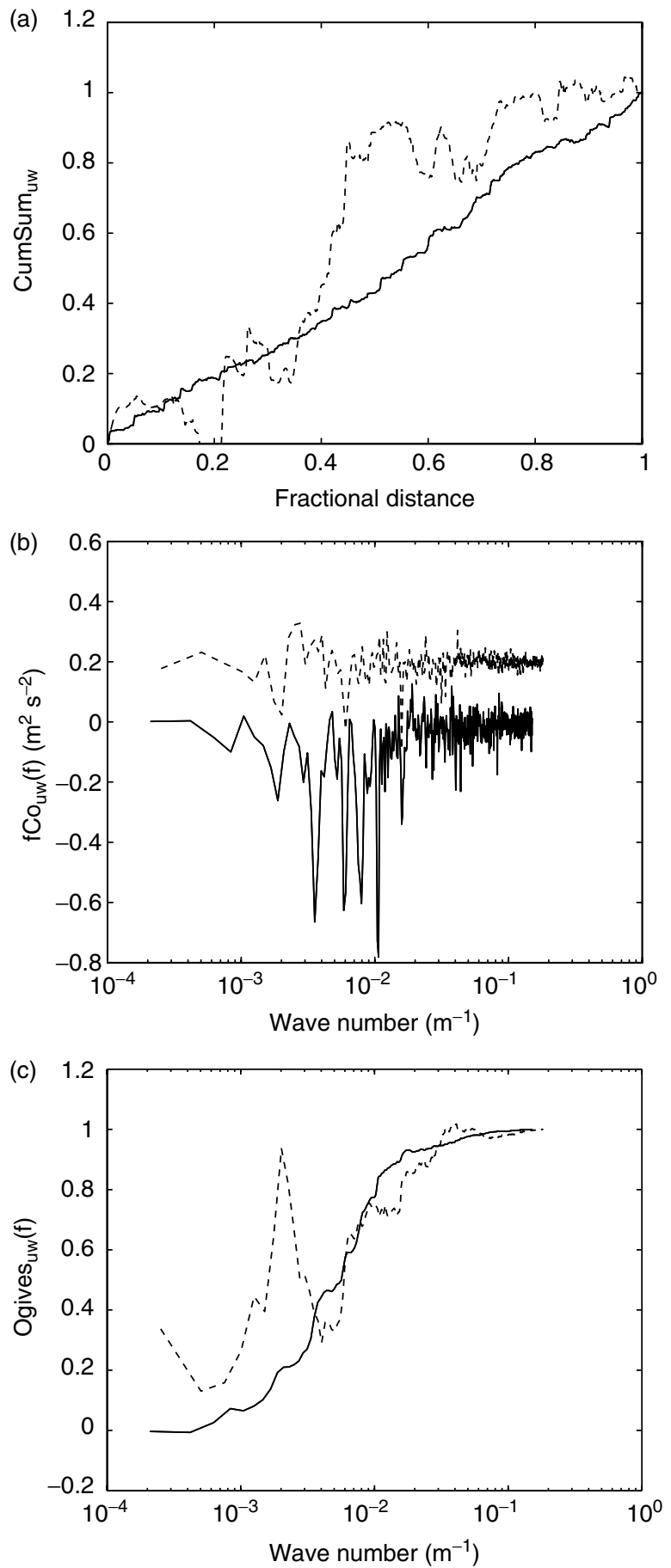

Figure 5. Quality control of the along-wind covariance, $u^{\prime} w^{\prime}$, for a good run (solid line) and a discarded run (dashed line). (a) The cumulative summation as a function of fractional distance. (b) The frequencyweighted cospectra as a function of the wavenumber. The curve for discarded run is offset by $0.2 \mathrm{~m}^{2} \mathrm{~s}^{-2}$. (c) The ogives as a function of the wavenumber. The cumulative summation is normalized by the total covariance and the ogives by the total cospectra.

\section{Eddy fluxes}

The high-frequency wind, temperature and humidity data from the accepted flux runs are used to calculate the wind stress, sensible and latent heat flux from the ocean to the atmosphere using (1)-(3). The $10 \mathrm{~m}$ air-sea exchange coefficients of
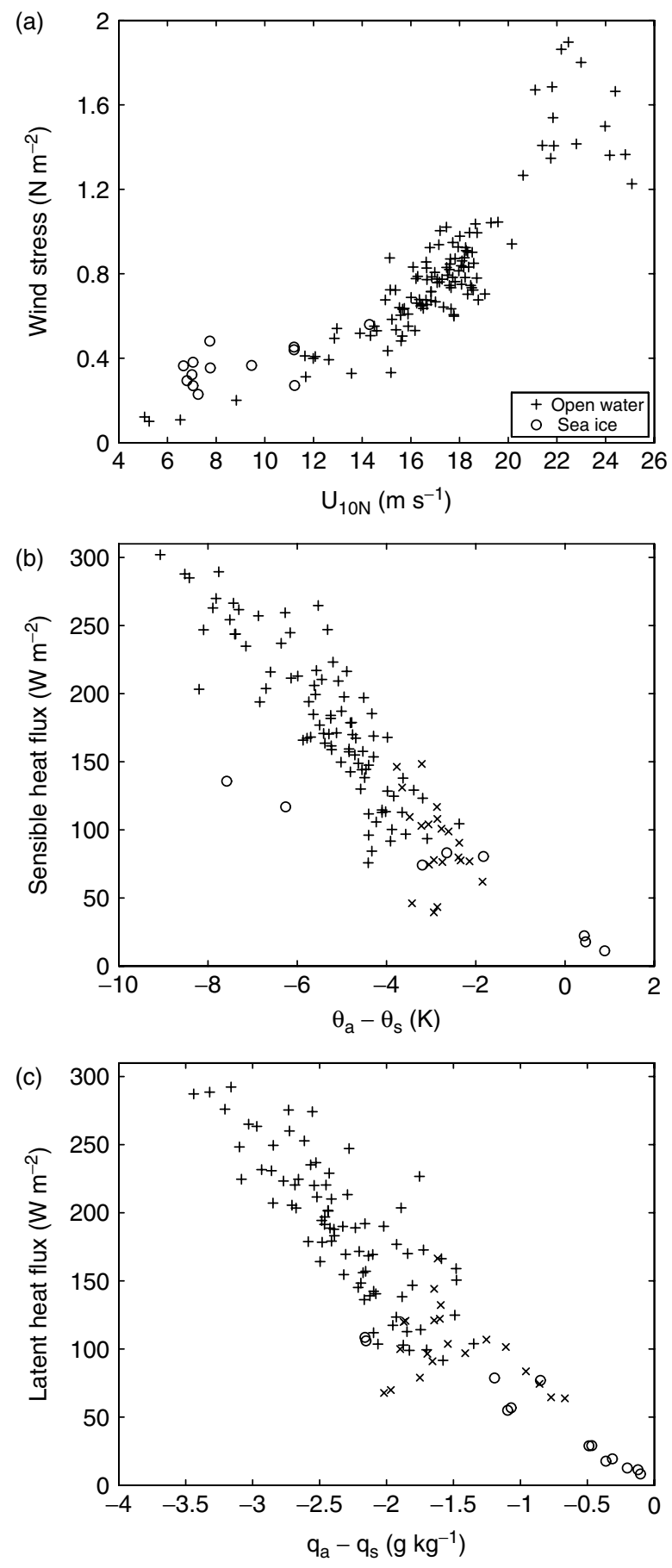

Figure 6. (a) Wind stress $\left(\mathrm{N} \mathrm{m}^{-2}\right)$ as a function of $U_{10 \mathrm{~N}}\left(\mathrm{~m} \mathrm{~s}^{-1}\right)$, (b) sensible heat flux $\left(\mathrm{W} \mathrm{m}^{-2}\right)$ as a function of air-sea potential temperature difference $(\mathrm{K})$ and (c) latent heat flux $\left(\mathrm{W} \mathrm{m}^{-2}\right)$ as a function of air-sea humidity difference $\left(\mathrm{g} \mathrm{kg}^{-1}\right)$. Flux runs over open water are represented by plus signs, with the exception of the B271 data that are represented by crosses in (b) and (c). The flux runs affected by sea ice are represented by circles.

momentum, heat and moisture are then estimated from (17)-(19).

Figure 6 shows the eddy covariance estimates of wind stress, sensible and latent heat fluxes. $U_{10 \mathrm{~N}}$ ranges from 5 to $25 \mathrm{~m} \mathrm{~s}^{-1}$, exceeding the range from RV Knorr during FASTEX (Persson et al., 2005) by $5 \mathrm{~m} \mathrm{~s}^{-1}$ at the upper end. The wind stress over open water increases roughly 
as $U_{10 \mathrm{~N}}{ }^{2}$ resulting in a large range of wind stresses from 0.2 to $1.9 \mathrm{~N} \mathrm{~m}^{-2}$. The largest wind speeds were measured during B268 and B277 in near-neutral conditions. At these high wind speeds, there is a large variability in the measured wind stress; in the $U_{10 \mathrm{~N}}$ interval $21-25 \mathrm{~m} \mathrm{~s}^{-1}$ the wind stress varies from 1.23 to $1.90 \mathrm{~N} \mathrm{~m}^{-2}$.

The sensible and latent heat flux vary linearly with differences in temperature and specific humidity. The B271 data for sensible and latent heat, represented by crosses in Figures 6(a) and (b), fall well within the ranges shown in the figures. The best linear fit to the sensible heat flux data over open water for all missions except $\mathrm{B} 271$ is $S H=-34.1\left(\theta_{\mathrm{a}}-\theta_{\mathrm{s}}\right)-2.2$. This best linear fit cuts through $\left(\theta_{\mathrm{a}}-\theta_{\mathrm{s}}\right)=-0.06 \mathrm{~K}$ when $S H=0 \mathrm{~W} \mathrm{~m}{ }^{-2}$, suggesting that the Heimann upwelling temperature is a good approximation to the SST. The best linear fit for all the data, including the OSTIA SST for B271, has a slightly larger residual: $\left(\theta_{\mathrm{a}}-\theta_{\mathrm{s}}\right)=-0.18 \mathrm{~K}$. However, as the B271 data have no impact on the best linear fit of the latent heat flux, the OSTIA correction factor seems reasonable.

The heat fluxes range from 50 to $300 \mathrm{~W} \mathrm{~m}^{-2}$. The sensible and latent heat flux vary in a similar manner, resulting in total heat flux varying from 100 to $600 \mathrm{~W} \mathrm{~m}^{-2}$. At its maximum, this total heat flux from the ocean to the atmosphere is about double the measured downward clear-sky short-wave radiation.

There are only a few data points in regions where the ocean was partly or fully ice covered (see Figure 1). These data points are characterized by low to moderate wind speed, small air-sea gradients in temperature and humidity and thus low air-sea fluxes. The exceptions are two runs with large air-sea temperature gradients (Figure 6b). These two runs are at the ice edge where there may have been little sea ice present, resulting in relatively high SST and thus a large air-sea temperature difference.

The $10 \mathrm{~m}$ neutral exchange coefficients for each flux run over open water are shown in Figure 7. It is clear from the figure that the majority of our data lie in a relatively narrow range of $U_{10 \mathrm{~N}}$, and encompass quite a large range of exchange coefficients. Note that the flux runs with $U_{10 \mathrm{~N}}<10 \mathrm{~m} \mathrm{~s}^{-1}$ are all from mission B271 flying in low wind speeds close to the ice edge with the air coming off the ice (northwesterly $\sim 5-6 \mathrm{~m} \mathrm{~s}^{-1}$ at flight level) at a proximity that may be impacting the drag coefficient.

The sampling error of a turbulent flux in stationary conditions can be expressed as

$$
\frac{\sigma_{F}}{\bar{F}}=\alpha_{F} z^{1 / 2} U^{-1 / 2} \Upsilon^{-1 / 2}
$$

where $F$ is a turbulent flux, such as $\overline{u^{\prime} w^{\prime}}, \sigma_{F}$ is the standard deviation of the flux, $z$ is the altitude $(\mathrm{m})$, $U$ is the speed of advection of the turbulence past the probe $\left(\mathrm{m} \mathrm{s}^{-1}\right)$ and $\Upsilon$ is the sampling interval (s) (e.g. Drennan et al., 2007). $\alpha_{F}$ is a constant, which is estimated in Donelan (1990) as 5.5, 8.0 and 6.6 for $F=\overline{u^{\prime} w^{\prime}}, \overline{w^{\prime} \theta^{\prime}}$ and $\overline{w^{\prime} q^{\prime}}$, respectively. The sampling (a)

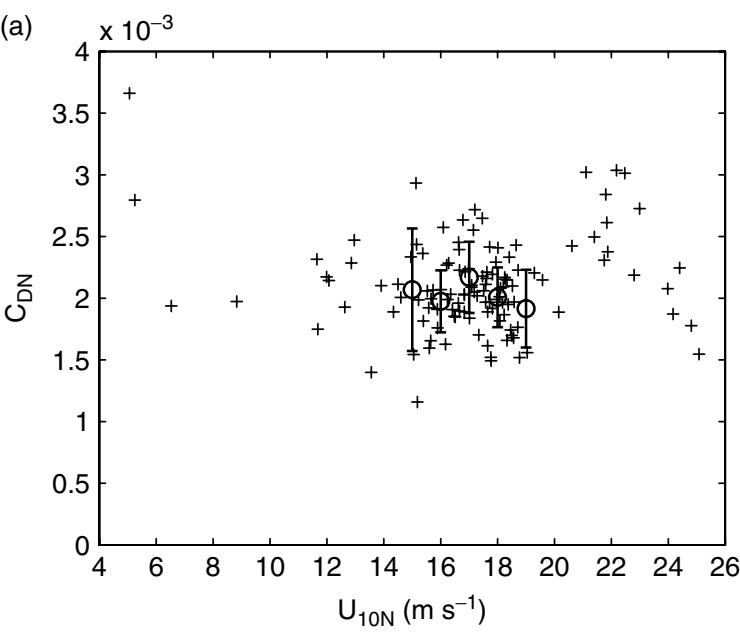

(b)

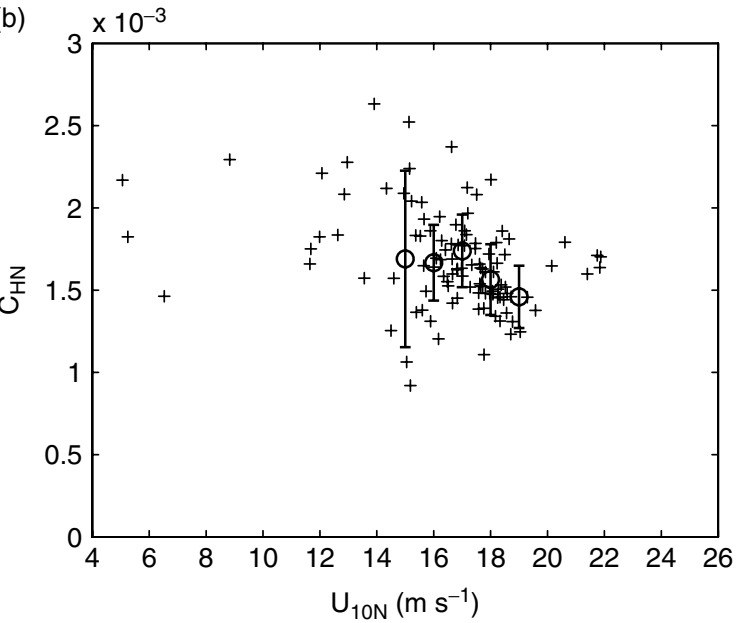

(c)

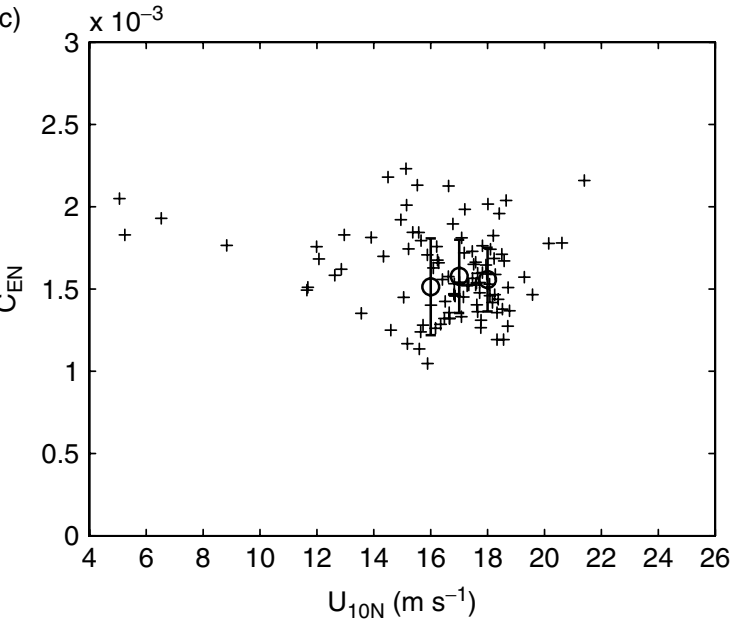

Figure 7. The $10 \mathrm{~m}$ neutral exchange coefficients over open water for (a) momentum, (b) sensible heat and (c) latent heat as functions of the $10 \mathrm{~m}$ neutral wind speed $\left(\mathrm{m} \mathrm{s}^{-1}\right)$. The $1 \mathrm{~m} \mathrm{~s}^{-1}$ bin-mean values are shown with circles and the error bars show one standard deviation. Only bins with at least 10 data points are shown.

errors of the GFDex turbulent fluxes over open water were estimated from (21) and compared to the variability in the data. The measurements were carried out at $z=\sim 39 \mathrm{~m}$, at $\sim 100 \mathrm{~m} \mathrm{~s}^{-1}$ relative wind speed and $\Upsilon=120 \mathrm{~s}$. The expected variability and the measured variability are shown in Table II. The measured variability 
Table II. Expected and measured sampling variability.

\begin{tabular}{lcc}
\hline Parameter & Expected (\%) & Measured (\%) \\
\hline$\overline{u^{\prime} w^{\prime}}$ & 31 & 44 \\
$\overline{w^{\prime} \theta^{\prime}}$ & 46 & 38 \\
$\overline{w^{\prime} q^{\prime}}$ & 37 & 35 \\
\hline
\end{tabular}

is largely consistent with the expected variability. The larger measured variability in the momentum flux is due to the large spread of the relative few observations at high wind speeds.

Although the neutral $10 \mathrm{~m}$ wind speed of the flux runs varies between 5 and $25 \mathrm{~m} \mathrm{~s}^{-1}, 80 \%$ of the flux runs have $U_{10 \mathrm{~N}}$ in the range $14-19 \mathrm{~m} \mathrm{~s}^{-1}$. The data are binned into $1 \mathrm{~m} \mathrm{~s}^{-1}$ bins for wind speeds where at least 10 data points are available (Figure 7). A comparison of the bin-mean values and the bin-median values shows little difference between the two bin types (not shown).

The $10 \mathrm{~m}$ neutral mean drag coefficients show little variation with wind speed, for the binned range $15-19 \mathrm{~m} \mathrm{~s}^{-1}: C_{\mathrm{DN}}=(2.04 \pm 0.30) \times 10^{-3}$, with one standard deviation. The GFDex values are at the upper end of observed drag coefficients but comparable to the FASTEX eddy covariance values measured on board the RV Knorr and in line with the discussion in Fairall et al. (2003). They discuss $C_{\mathrm{DN}}$ values at high wind speeds (focusing on a $U_{10 \mathrm{~N}}$ of $20 \mathrm{~m} \mathrm{~s}^{-1}$ ) and quote values of $1.93 \times 10^{-3}$ (Smith, 1980), $1.92 \times 10^{-3}$ or $1.99 \times 10^{-3}$ (Taylor and Yelland, 2000), and $2.30 \times 10^{-3}$ and $2.07 \times 10^{-3}$ for eddy covariance and inertial dissipation. We can see that our drag coefficients are broadly consistent with these datasets and corroborate previous studies that have shown higher exchange coefficients from the eddy covariance technique, as compared to the inertial dissipation method (e.g. see figure 8 of Persson et al., 2005). It is likely that the reason for the absence of the expected increase in the drag coefficient with increasing $10 \mathrm{~m}$ neutral wind speed is the narrowness of the measured wind speed range.

The bin-mean $10 \mathrm{~m}$ neutral heat exchange coefficients in the $U_{10 \mathrm{~N}}$ range $15-19 \mathrm{~m} \mathrm{~s}^{-1}$ decreases with wind speed from $C_{\mathrm{HN}}=(1.69 \pm 0.54) \times 10^{-3}$ to $C_{\mathrm{HN}}=(1.46 \pm 0.19) \times 10^{-3}$, with one standard deviation. Again, because of the narrow wind speed range no conclusions can be drawn from this decrease. In general, the coefficients are rather large, compared with values from other field campaigns; the mean value for the range is $(1.63 \pm 0.28) \times 10^{-3}$. However, it should be noted that there have been few previous observations of $C_{\mathrm{HN}}$ in open-ocean conditions in high wind speeds.

The bin-mean moisture exchange coefficients in the $U_{10 \mathrm{~N}}$ range $15-19 \mathrm{~m} \mathrm{~s}^{-1}$ are almost constant with wind speed. The mean value is $C_{\mathrm{EN}}=(1.57 \pm 0.26) \times 10^{-3}$, with one standard deviation. Again, these values are at the upper end of reported moisture coefficients.

Figure 8 shows our exchange coefficients together with the FASTEX (Persson et al., 2005), HEXOS (DeCosmo et al., 1996), SOWEX (Banner et al., 1999) and CBLAST data (French et al., 2007; Drennan et al., 2007). It is clear from the comparison to the other datasets that even though the GFDex measurements are at the upper end of reported exchange coefficients, they are by no means outside the observed range. The majority of the GFDex drag coefficients are within the range covered by the FASTEX and HEXOS data whereas at high wind speeds the coefficients are similar to the CBLAST data. The moisture exchange coefficients binned values are higher than in previous studies. However, the last FASTEX binned value is comparable to the GFDex values. The heat exchange coefficients are high compared to FASTEX, HEXOS and SOWEX, but note that there are few data points from the previous field campaigns at wind speeds greater than about $16 \mathrm{~m} \mathrm{~s}^{-1}$. It is worth noting that the CBLAST observations were obtained at much higher altitude than the GFDex observations, only six of the flux runs are at altitudes less than $100 \mathrm{~m}$ while all the GFDex flux runs are at $32-51 \mathrm{~m}$. Figure 8 emphasizes the large variability in measured exchange coefficients due to the sampling of variables of such turbulent nature.

Spatial maps of the exchange coefficients are shown in Figure 9. Note that, for clarity, the data from B277 are not plotted, as the low-level flight leg is in the same location as the northern low-level leg of B278.

Despite the fact that there are only 14 flux runs that are defined as being over partly or fully ice covered ocean and there are large uncertainties associated with these data, it is worth making a few comments regarding the drag coefficients in this region (see Figure 9a). It has previously been shown that the drag coefficient can be larger over ice than open water and that it varies as a function of ice concentration (Anderson, 1987). The GFDex observations, although few, are in agreement with these previous observations. The $10 \mathrm{~m}$ neutral drag coefficient, $C_{\mathrm{DN}}$, is larger over sea ice than over open water, varying in the range $1.67 \times 10^{-3}$ in regions of little or no sea ice to $6.29 \times 10^{-3}$ where the sea-ice concentration is the highest. A large variation in the data is to be expected when sampling a highly turbulent feature over an inhomogeneous surface. Also, because of the small number of runs, it is not surprising that our values are larger than those reported in climatological studies (e.g. Anderson, 1987; Andreas et al., 1984). Because of the large uncertainties in the surface temperature and surface humidity over partly or fully ice covered ocean, the exchange coefficients of heat and moisture are not shown.

Over open water, there is no significant spatial variability in the coefficients. The two flux runs in B271 closest to the sea ice edge have higher drag coefficients than those farther away. This may be related to the wind blowing off the sea ice and having some sort of 'memory' of the sea ice surface. $C_{\mathrm{HN}}$, and to some extent $C_{\mathrm{EN}}$, are higher during B271 than the other two missions. B271 is characterized by higher $\theta_{*}$ (less negative) than the other missions, smaller air-sea differences in temperature and lower $U_{10 \mathrm{~N}}$ in the region closest to the ice edge. These differences are not entirely balanced, resulting in higher $C_{\mathrm{HN}}$; see (15). The surface temperature in B271 
(a)

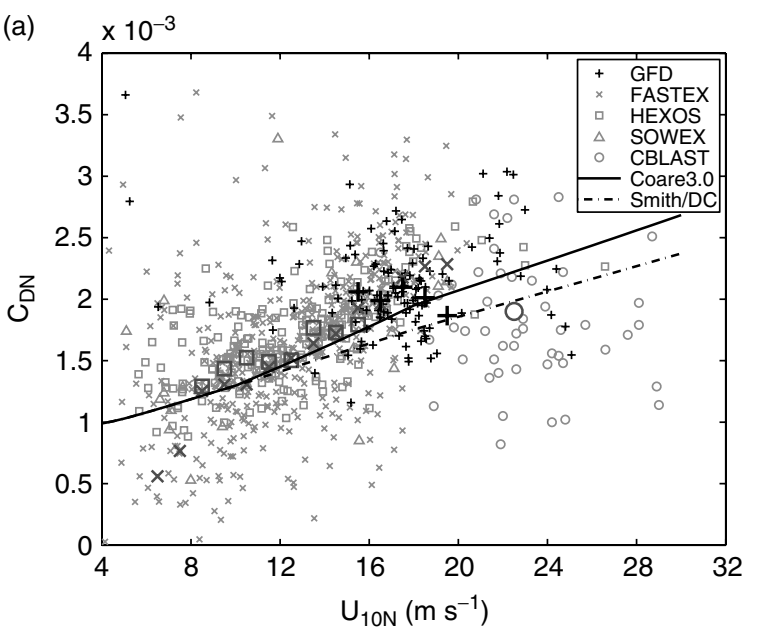

(b)

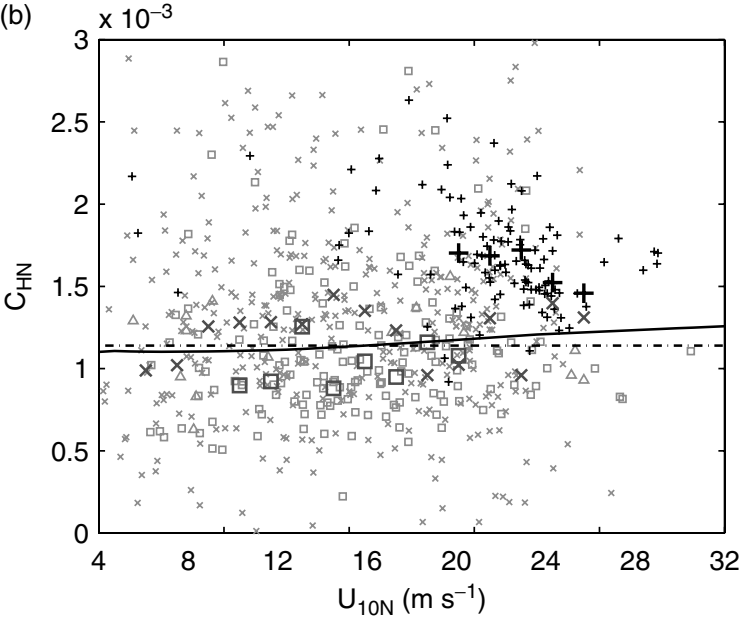

(c)

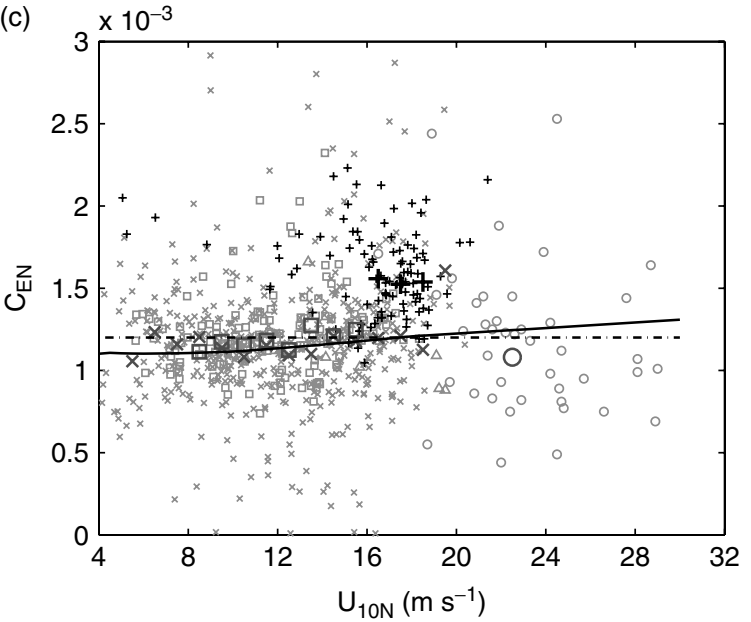

Figure 8 . The $10 \mathrm{~m}$ neutral exchange coefficients over open water for (a) momentum, (b) sensible heat and (c) latent heat as functions of the $10 \mathrm{~m}$ neutral wind speed $\left(\mathrm{m} \mathrm{s}^{-1}\right)$. The GFDex data points are shown with plus signs, the FASTEX data (Persson et al., 2005) with crosses, the HEXOS data (DeCosmo et al., 1996), corrected according to Fairal et al. (2003) with squares, the SOWEX data (Banner et al., 1999) with triangles and the CBLAST data (French et al., 2007; Drennan et al. 2007) with circles. The $1 \mathrm{~m} \mathrm{~s}^{-1}$ bin-median values are shown for bins with at least 10 data points. The solid curve is the COARE 3.0 algorithm (Fairall et al., 2003) and the dashed line is the Smith (1988) algorithm using the exchange coefficients from DeCosmo et al. (1996). is retrieved from the OSTIA dataset, which may affect the heat exchange coefficient. It is possible that the bias correction of the OSTIA data may be too large, resulting in smaller air-sea temperature differences. However, the applied bias correction is supported by the fact that smaller correction would result in non-zero latent heat fluxes when $q_{\mathrm{a}}-q_{\mathrm{s}}=0$. Another plausible explanation is that the conditions during B271 were less extreme (e.g. smaller waves and less sea spray) than during the other two missions.

\section{Discussion and conclusions}

One of the goals of the GFDex was to obtain estimates of the air-sea fluxes of momentum, heat and moisture over Denmark Strait and the Irminger Sea. These fluxes may be of great importance for the ocean below, as it has been suggested that the thermohaline circulation overturns in the Irminger Sea. During the GFDex, 12 missions were flown, whereof five included low-level high-frequency measurements. These in situ observations are the first direct observations of air-sea fluxes in this region. They were made in cold-air outbreak, high wind speed conditions and thus make a valuable addition to the few ship-based datasets obtained in similar conditions.

The air-sea fluxes were estimated using the eddy covariance method for flux runs of $2 \mathrm{~min}$, approximately $12 \mathrm{~km}$, at 'minimum safe altitude', typically 30-50 m above the sea-surface. In total, there were 145 flux runs, 131 over open water and the remainder over the marginal ice zone or sea ice. Strict quality control resulted in 120 runs available for wind stress calculations, 109 for sensible heat flux calculations and 102 for latent heat calculations, all over open water.

Most of the data were obtained in high wind speeds, $80 \%$ of the flux runs have a $10 \mathrm{~m}$ neutral wind speed of $14-19 \mathrm{~m} \mathrm{~s}^{-1}$. The wind stress over open water varies approximately with $U_{10 \mathrm{~N}}^{2}$ from 0.2 to $1.9 \mathrm{~N} \mathrm{~m}^{-2}$. The eddy covariance estimates of sensible and latent heat range from 50 to $300 \mathrm{~W} \mathrm{~m}^{-2}$, resulting in the ocean losing in total $100-600 \mathrm{~W} \mathrm{~m}^{-2}$ to the atmosphere.

Inside the $15-19 \mathrm{~m} \mathrm{~s}^{-1} 10 \mathrm{~m}$ neutral wind speed range, $C_{\mathrm{DN}}=(2.04 \pm 0.30) \times 10^{-3}$ and $C_{\mathrm{EN}}=(1.57 \pm$ $0.26) \times 10^{-3}$ while $C_{\mathrm{HN}}$ decreases with wind speed from $(1.69 \pm 0.54) \times 10^{-3}$ to $(1.46 \pm 0.19) \times 10^{-3}$ (mean value \pm one standard deviation). Neither the variation of $C_{\mathrm{HN}}$ nor the lack of variation in $C_{\mathrm{DN}}$ is particularly significant given the limited $U_{10 \mathrm{~N}}$ range. The exchange coefficients are at the upper end of those observed in previous studies, although still within the range of values reported.

The dependency of the exchange coefficients on the wind speed is currently a topic of debate. Although it is widely accepted that $C_{\mathrm{DN}}$ increases with wind speed up to some point in the range $20-30 \mathrm{~m} \mathrm{~s}^{-1}$, recent studies have suggested there is a levelling off in $C_{\mathrm{DN}}$, caused by flattening of the sea-surface as waves are 'torn off' (e.g. French et al., 2007; Powell et al., 2003; Bye and Jenkins, 2006). Our dataset has a relatively small range 

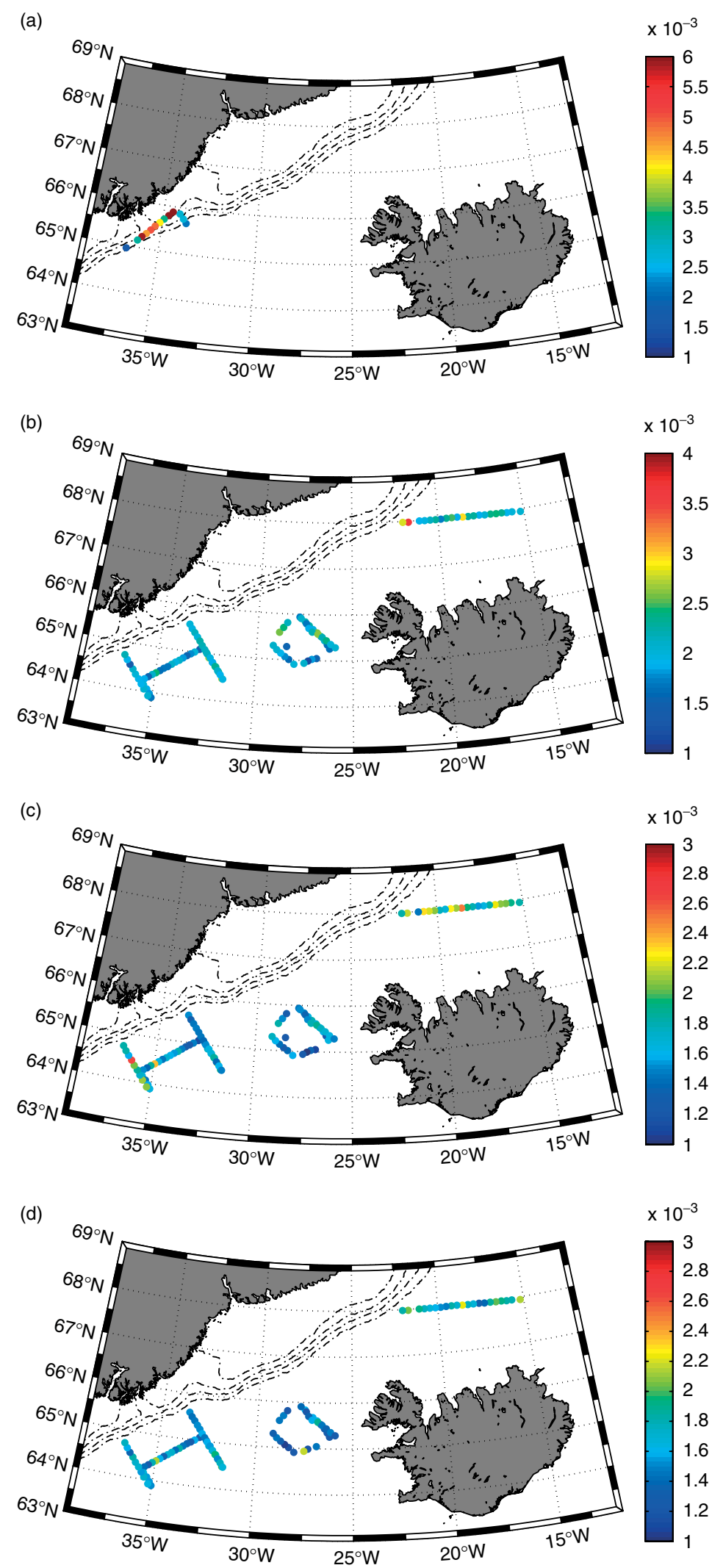

Figure 9. The $10 \mathrm{~m}$ neutral exchange coefficients for (a) momentum over ice, (b) momentum over open water, (c) heat over open water and (d) humidity over open water (missions B271, B276 and B278). The dashed lines show the OSTIA sea-ice concentration on 5 March 2007 , from 0.2 to 0.8 
in wind speed and no observations at $U_{10 \mathrm{~N}}>30 \mathrm{~m} \mathrm{~s}^{-1}$. Hence, while it would be misleading to suggest our $C_{\mathrm{DN}}$ results confirm levelling off, Figure 8(a) illustrates some reduction in $C_{\mathrm{DN}}$ for the highest $U_{10 \mathrm{~N}}$ data, which is consistent with the aforementioned studies.

The impact of high wind speed and thus the sea state and spray on $C_{\mathrm{HN}}$ and $C_{\mathrm{EN}}$ is less well known. Andreas and DeCosmo (2002) and Andreas et al. (2008) argue that, contrary to earlier studies by, for example, Makin (1998) and Janssen (1997), sea spray is an important contributor to heat fluxes for wind speeds as low as 11-13 $\mathrm{m} \mathrm{s}^{-1}$ and increases in importance with wind speed, as a result of heat and moisture transfer occurring both at the air-sea interface and at the surface of spray droplets. During most of the low-level flight legs, the sea surface was rough with streaks of sea spray and for the higher wind speed events the significant wave height was estimated at $5-10 \mathrm{~m}$. Thus, additional heat and moisture flux due to sea spray could explain why the measured exchange coefficients of heat and moisture are larger than observed in regions where wave heights are lower, for example, in the North Sea (during HEXOS) where one can expect less wave growth than at the same wind speeds over the open ocean and thus less sea spray (Andreas and DeCosmo, 2002). A comprehensive analysis of the effects of sea spray on surface heat and momentum exchange using the GFDex data is planned, but is outside the scope of this article. It is intended to make use of the in situ particle detection measurements obtained during the GFDex in this regard.

The largest source of uncertainty in the GFDex data is the estimate of the SST, that is, the Heimann upwelling brightness temperature measurements and, in the case of B271, the satellite-based OSTIA temperatures. However, the fact that the best linear fit to the sensible heat flux nearly cuts through $\theta_{\mathrm{a}}-\theta_{\mathrm{s}}=0 \mathrm{~K}$ when $S H=0 \mathrm{~W} \mathrm{~m}^{-2}$ indicates that the Heimann measurements are consistent with the turbulent flux estimates. The corrected OSTIA surface temperature increases the temperature residual slightly but has no effect on the humidity residual. This suggests that the corrected OSTIA is a good approximation to the SST when no aircraft measurements are available.

Further analysis and model simulations of the GFDex missions are under way. These may be able to answer questions outside the scope of this article (e.g. if any roll vortices were present and their effect on the boundary layer). However, the air-sea flux data presented here are not only valuable for case studies of individual missions but also for comparisons of the GFDex data and other observations (e.g. remote sensing observations), as well as validations of numerical model data and reanalysis in this region of sparse direct air-sea flux observations (Renfrew et al., 2009). The data are easily presented as either time series or spatial maps. Figure 10 shows a time-series comparison of the eddy fluxes and bulk fluxes based on the COARE 3.0 (Fairall et al., 2003) algorithm and the Smith (1988) algorithm with DeCosmo et al. (1996) coefficients corrected. The figure shows clearly
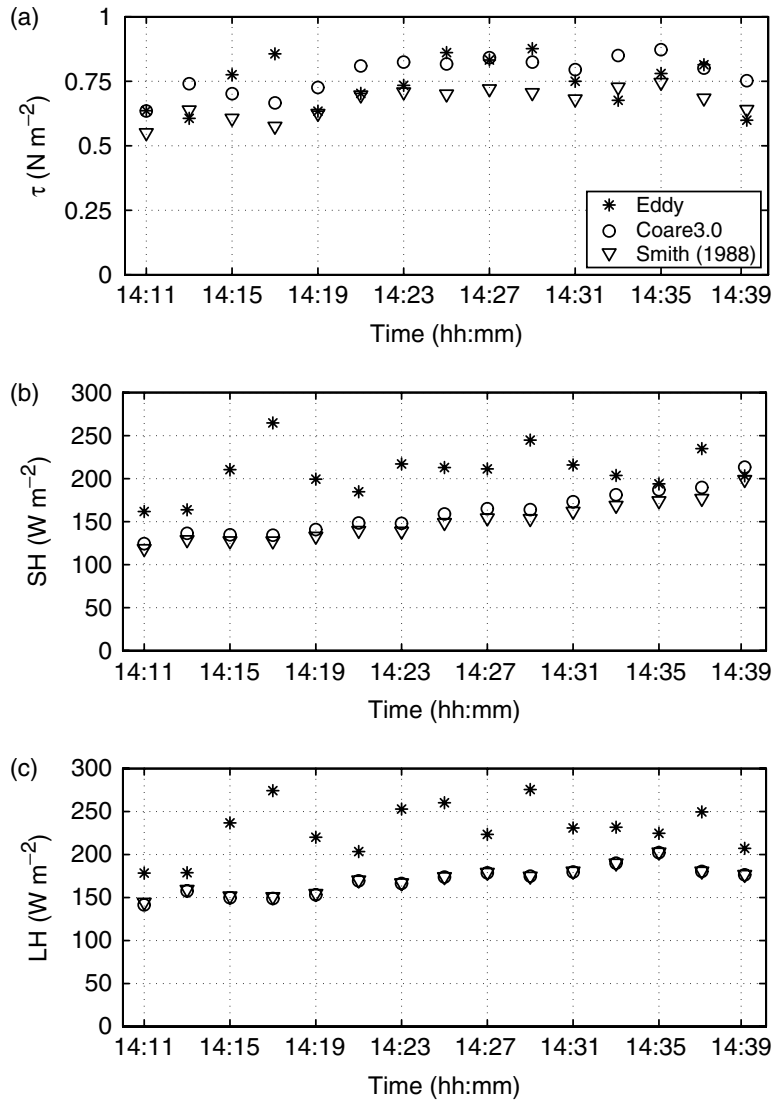

Figure 10. Time series of (a) wind stress $\left(\mathrm{N} \mathrm{m}^{-2}\right)$, (b) sensible heat flux $\left(\mathrm{W} \mathrm{m}^{-2}\right)$ and $(\mathrm{c})$ latent heat flux $\left(\mathrm{W} \mathrm{m}^{-2}\right)$ during low-level flight leg 6 of B276, 5 March 2007. The stars represent the eddy covariance fluxes, the circles COARE 3.0 bulk fluxes (Fairall et al., 2003) and the triangles bulk fluxes based on the Smith (1988) algorithm using the exchange coefficients of DeCosmo et al. (1996), corrected according to Fairall et al. (2003).

that while the eddy covariance and bulk wind stresses are comparable, the bulk heat fluxes are systematically lower than observed, the difference sometimes as much as $50 \mathrm{~W} \mathrm{~m}^{-2}$.

The average drag coefficient is similar to the COARE 3.0 drag coefficient (Fairall et al., 2003). However, the exchange coefficients of heat and moisture exceed the values used in COARE 3.0 and other parametrization schemes, as suggested by Figure 10. Flux parametrization schemes are based on large observational databases, mainly ship-based observations, and many of these observations are from the less direct inertial dissipation method. Most of these observations are at low-moderate wind speeds (e.g. less than $2 \%$ of the momentum and moisture flux data in the ETL database are at wind speeds greater than $15 \mathrm{~m} \mathrm{~s}^{-1}$ ), and within the tropics where sensible heat flux measurements are sparse or negligible. The GFDex observations, however, are direct aircraft-based observations at high latitudes, in high wind speed conditions and in a region where (during the winter) there are frequently large air-sea temperature and humidity gradients. These are extreme conditions and the data can be expected to diverge from average values derived from large datasets. Indeed, the GFDex air-sea flux observations suggest that current parametrization schemes may 
underestimate the air-sea fluxes in such conditions, perhaps because of the lack of flux contribution from sea spray or unusual wave conditions. These data emphasize the importance of direct measurements of air-sea fluxes in regions where the fluxes are thought to be of importance for the atmospheric and/or oceanic circulations (e.g. in regions of open-ocean convection or tropical storms). The lack of direct observations in extreme situations may result in an underestimation of the exchange coefficients in such regions and thus an underestimation of model fluxes. The GFDex air-sea turbulent flux dataset is an important addition to the small number of datasets obtained in such high wind speed conditions.

\section{Acknowledgements}

The authors would like to acknowledge the efforts of everyone involved in planning and carrying out the GFDex. The support of FAAM, DirectFlight and Avalon during the field campaign was greatly appreciated. In particular, we would like to thank Phil Brown for kindly supplying us with the B079 intercomparison data and for carrying out the B263 calibration flight, Alan Woolley for postprocessing the Lyman- $\alpha$ humidity data, Ian Brooks for the McCarthy algorithm Matlab script and William Drennan for the HEXOS data. We would also like to thank them all, together with Gordon Inverarity, John King, Tom Lachlan-Cope, G. W. Kent Moore and Simon Newman, for valuable discussions, and we thank two anonymous reviewers for helpful comments. We would like to thank Chris W. Fairall and P. Ola G. Persson for the FASTEX data. This study was funded by the Natural Environmental Research Council (NERC; NE/C003365/1).

\section{References}

Anderson RJ. 1987. Wind stress measurements over rough sea ice during the 1984 Marginal Ice Zone Experiment. J. Geophys. Res. 92(C7): 6933-6941.

Andreas EL, DeCosmo J. 2002. The signature of sea spray in the HEXOS turbulent heat flux data. Boundary-Layer Meteorol. 103: 303-333.

Andreas EL, Tucker WB, Ackley SF. 1984. Atmospheric boundarylayer modification, drag coefficient, and surface heat flux in the Antarctic marginal ice zone. J. Geophys. Res. 89(NC1): 649-661.

Andreas EL, Persson POG, Hare JE. 2008. A bulk turbulent air-sea flux algorithm for high-wind, spray conditions. J. Phys. Oceanogr. 38: $1581-1596$.

Bacon S, Reverdin G, Rigor IG, Snaith HM. 2002. A freshwater jet on the east Greenland shelf. J. Geophys. Res. 107: 3068 (doi:10.10299/2001JC000935).

Banner ML, Chen W, Walsh EJ, Jensen JB, Lee S, Fandry C. 1999. The Southern ocean experiment. Part I: Overview and mean results. J. Phys. Oceanogr. 29: 2130-2145.

Black PG, D'Asaro EA, Drennan WM, French JR, Niller PP, Sanfort TB, Terril EJ, Walsh EJ, Zhang JA. 2007. Air-sea exchange in hurricanes: Synthesis of observations from the coupled boundary layer air-sea transfer experiment. Bull. Am. Meteorol. Soc. 88: 357-374 (doi:10.1175/BAMS-88-3-357).

Brown EN, Friehe CA, Lenschow DH. 1983. Pressure fluctuations on the nose of an aircraft for measuring air motion. J. Clim. Appl. Meteorol. 22: 171-180.

Brunke MA, Zhou M, Zeng X, Andreas EL. 2006. An intercomparison of bulk aerodynamic algorithms used over sea ice with data from the Surface Heat Budget for the Arctic Ocean (SHEBA) experiment. J. Geophys. Res. 111(C09001):. (doi:10.1029/2005JC002907).

Bumke K, Karger U, Uhlig K. 2002. Measurements of turbulent fluxes of momentum and sensible heat over the Labrador Sea. J. Phys. Oceanogr. 32: 401-410.

Businger JA. 1982. Equations and concepts. Pp. 1-36 in Atmospheric Turbulence and Air Pollution Modeling. Reidel: Dordrecht.

Bye JAT, Jenkins AD. 2006. Drag coefficient reduction at very high wind speeds. J. Geophys. Res. 111(C03024): (doi:10.1029/2005JC003114).

DeCosmo J, Katsaros KB, Smith SD, Anderson RJ, Oost WA, Bumke K, Chadwick H. 1996. Air-sea exchange of water vapor and sensible heat: The Humidity Exchange Over the Sea (HEXOS) results. J. Geophys. Res. 101(C5): 12001-12016.

Donelan MA. 1990. Air-sea interaction. Pp. 239-292 in The Sea. Wiley-Interscience: New York.

Drennan WM, Zhang JA, French JR, McCormick C, Black PG. 2007. Turbulent fluxes in the hurricane boundary layer. Part II: Latent heat flux. J. Atmos. Sci. 64: 1103-1115 (doi:10.1175/JAS3889.1).

Dyer AJ. 1974. A review of flux-profile relations. Boundary-Layer Meteorol. 7: 363-372.

Eymard L, Caniaux G, Dupuis H, Prieur L, Giordani H, Troadec R, Bessemoulin P, Lachaud G, Bouhours G, Bourras D, Guérin C, Borgne PL, Brisson A, Marsouin A. 1999. Surface fluxes in the North Atlantic current during CATCH/FASTEX. Q. J. R. Meteorol. Soc. 125: 3563-3599.

Fairall CW, Bradley EF, Hare JE, Grachev AA, Edson JB. 2003. Bulk parametrization of air-sea fluxes: Updates and verification for the COARE algorithm. J. Climate 16: 571-591.

French JR, Drennan WM, Zhang JA, Black PG. 2007. Turbulent fluxes in the hurricane boundary layer. Part I: Momentum flux. J. Atmos. Sci. 64: 1089-1102.

Inverarity GW. 2000. Correcting airborne temperature data for lags introduced by instruments with two-time-constant responses. J. Atmos. Oceanic Technol. 17: 176-184.

Janssen PAEM. 1997. Effect of surface gravity waves on the heat flux. Technical Report 239. ECMWF: Reading, UK.

Janssen PAEM. 1999. On the effect of ocean waves on the kinetic energy balance and consequences for the inertial dissipation technique. J. Phys. Oceanogr. 29: 530-534.

Killworth PD. 1983. Deep convection in the world ocean. Rev. Geophys. Space Phys. 21: 1-26.

Large WG, Pond S. 1981. Open ocean momentum flux measurements in moderate to strong winds. J. Phys. Oceanogr. 11: 324-336.

McCarthy J. 1973. A method for correcting airborne temperature data for sensor response. J. Appl. Meteorol. 12: 211-214.

Makin VK. 1998. Air-sea exchange of heat in the presence of wind waves and spray. J. Geophys. Res. 103(C1): 1137-1152.

Marshall J, Schott F. 1999. Open ocean deep convection: Observations, theory and models. Rev. Geophys. 37: 1-64.

Masuda K, Takashima T, Takayama Y. 1988. Emissivity of pure seawater for the model sea surface in the infrared window regions. Remote Sensing Environ. 24: 313-329.

Nicholls S. 1978. Measurements of turbulence by an instrumented aircraft in a convective atmospheric boundary layer over the sea. Q. J. R. Meteorol. Soc. 104: 653-676.

Nicholls S, Leighton J, Barker R. 1990. New fast response instrument for measuring total water content from aircraft. J. Atmos. Oceanic Technol. 7: 706-718.

Niclós R, Valor E, Caselles V, Coll C, Sánchez JM. 2005. In situ angular measurements of thermal infrared sea surface emissivity: Validation of models. Remote Sensing Environ. 94: 83-93.

Paulson CA. 1970. The mathematical representation of wind speed and temperature in the unstable atmospheric boundary layer. J. Appl. Meteorol. 9: 857-861.

Persson POG, Hare JE, Fairall CW, Otto WD. 2005. Air-sea interaction processes in warm and cold sectors of extratropical cyclonic storms observed during FASTEX. Q. J. R. Meteorol. Soc. 131: 877-912.

Pickart RS, Spall MA, Ribergaard MH, Moore GWK, Milliff RF. 2003a.. Deep convection in the Irminger Sea forced by the Greenland tip jet. Nature 424: 152-156.

Pickart RS, Straneo F, Moore GWK. 2003b. Is the Labrador Sea Water formed in the Irminger basin? Deep-Sea Res. I 50: 23-52. 
Pickart RS, Torres DJ, Fratantoni PS. 2005. The East Greenland spill jet. J. Phys. Oceanogr. 35: 1037-1053.

Powell MD, Vickery PJ, Reinhold TA. 2003. Reduced drag coefficient for high wind speeds in tropical cyclones. Nature 422 279-283.

Rauber RM, Stevens B, Ochs H, Knight C, Albrecht B, Blyth A Fairall C, Jensen J, Lasher-Trapp S, Mayol-Bracero O, Vali G, Anderson J, Baker B, Bandy A, Burnet E, Brenguier J, Brewer W, Brown P, Chuang P, Cotton W, Girolamo LD, Geerts B, Gerber H, Göke S, Gomes L, Heikes B, Hudson J, Kollias P, Lawson R Krueger S, Lenschow D, Nuijens L, O'Sullivan D, Rilling R, Rogers D, Siebesma A, Snodgrass E, Stith J, Thornton D, Tucker S, Twohy C, Zuidema P. 2007. Rain in shallow cumulus over the ocean: The RICO campaign. Bull. Am. Meteorol. Soc. 88 1912-1928.

Renfrew IA, Moore GWK, Kristjánsson JE, Ólafsson H, Gray SL, Petersen GN, Bovis K, Brown PRA, Føre I, Haine T, Hay C, Irvine EA, Lawrence A, Ohigashi T, Outten S, Pickart RS Shapiro M, Sproson D, Swinbank R, Woolley A, Zhang S. 2008 The Greenland Flow Distortion experiment. Bull. Am. Meteorol. Soc. 89: $1307-1324$.

Renfrew IA, Petersen GN, Sproson D, Moore GWK, Adiwidjaja H, Zhang S, North R. 2009. A comparison of aircraft-based surfacelayer observations during high wind speed conditions over Denmark Strait and the Irminger Sea with meteorological analyses and QuikSCAT winds. Q. J. R. Meteorol. Soc. 135: 2046-2066.

Smith SD. 1980. Wind stress and heat flux over the ocean in gale force winds. J. Phys. Oceanogr. 10: 709-726.
Smith SD. 1988. Coefficients for sea surface wind stress, heat flux and wind profiles as a function of wind speed and temperature. J. Geophys. Res. 93: 15467-15472.

Smith SD, Anderson RJ, Oost WA, Kraan C, Maat N, DeCosmo J, Katsaros KB, Bumke K, Hasse L, Chadwick HM. 1992. Sea surface wind stress and drag coefficients: The HEXOS results. BoundaryLayer Meteorol. 60: 109-142.

Stark JD, Donlon CJ, Martin MJ, McCulloch ME. 2007. OSTIA: An operational, high resolution, real time, global sea surface temperature analysis system. In OCEANS 2007 - Europe. IEEE: Piscataway, NJ (doi:10.1109/OCEANSE.2007.4302251).

Stull RB. 1988. An Introduction to Boundary Layer Meteorology. Kluwer Academic: Dordrecht.

Taylor PK, Yelland MJ. 2000. On the apparent 'imbalance' term in the turbulent kinetic energy budget. J. Atmos. Oceanic Technol. 17: 82-89.

Taylor PK, Yelland MJ. 2001. The dependence of sea surface roughness on the height and steepness of the waves. J. Phys. Oceanogr. 31: $572-590$.

Woolf DK, Challenor PG, Cotton PD. 2002. Variability and predictability of the North Atlantic wave climate. J. Geophys. Res. 107(C10): 3145 (doi:10.1029/2001JC001124).

Yelland M, Taylor PK. 1996. Wind stress measurements from the open ocean. J. Phys. Oceanogr. 26: 541-558.

Yelland MJ, Moat BI, Taylor PK, Pascal RW, Hutchings J, Cornell VC. 1998. Wind stress measurements from the open ocean corrected for airflow distortion by the ship. J. Phys. Oceanogr. 28: 1511-1526. 